\title{
NANOFÓSILES CALCÁREOS Y BIOESTRATIGRAFÍA DEL CRETÁCICO DEL SUDESTE DE LA CUENCA AUSTRAL, PATAGONIA, ARGENTINA
}

\author{
JUAN PABLO PÉREZ PANERA \\ División Paleozoología Invertebrados, Museo de La Plata, Paseo del Bosque s/n, B1900FWA, La Plata, Argentina \\ Consejo Nacional de Investigaciones Científicas (CONICET). perezpanera@gmail.com
}

\begin{abstract}
Resumen. Se realizó un estudio cuantitativo de los nanofósiles calcáreos del Cretácico en cinco localidades en el sector sudeste de la Cuenca Austral. A partir del análisis de las asociaciones recuperadas y la comparación con biozonaciones previas para el Océano Atlántico Austral, se identificaron asociaciones del Valanginiano-Hauteriviano temprano, Albiano temprano-Albiano medio, Albiano tardío-Cenomaniano, Coniaciano/Santoniano-Campaniano y Maastrichtiano tardío. Se interpretan dos discontinuidades en la secuencia cretácica por hiatos bioestratigráficos: una para el Hauteriviano tardío-Barremiano y otra para al menos el Turoniano. Las asociaciones del Cretácico Temprano son comparables a las registradas en el Plateau de Malvinas y se habrían desarrollado en una plataforma externa con aguas superficiales frías y alta disponibilidad de nutrientes, mientras que las asociaciones del Cretácico Tardío lo habrían hecho en una plataforma interna, con aguas superficiales frías a templadas y con características similares a las asociaciones de las cuencas Neuquina y del Colorado.
\end{abstract}

Palabras clave: Nanofósiles calcáreos. Cretácico. Bioestratigrafía. Cuenca Austral. Argentina.

Abstract. CRETACEOUS CALCAREOUS NANNOFOSSILS AND BIOSTRATIGRAPHY OF SOUTHEASTERN AUSTRAL BASIN, PATAGONIA, ARGENTINA. This study presents the results of a quantitative analysis of the calcareous nannofossils recovered in five localities in the southeastern sector of the Austral Basin. On the basis of the assemblages recovered and its comparison with previous biozonations for the Austral Atlantic Ocean, it was possible to identify Valanginian-early Hauterivian, early Albian-middle Albian, late AlbianCenomanian, Coniacian/Santonian-Campanian and late Maastrichtian assemblages. Two discontinuities evidenced by biostratigraphical hiatuses for the Cretaceous sequence were deduced: one for the late Hauterivian-Barremian and the other for at least the Turonian. The Early Cretaceous assemblages are comparable to those of the Falkland Plateau and they would be developed on an external platform having cold surface waters and high availability of nutrients. The Late Cretaceous assemblages are similar to those found in the Neuquina and Colorado basins and they would be developed on an internal platform having cold to temperate surface waters.

Key words: Calcareous nannofossils. Cretaceous. Biostratigraphy. Austral Basin. Argentina.

La Cuenca Austral o Magallánica se extiende, con una dirección NNO-SSE, sobre casi toda la Patagonia austral al sur del paralelo $47^{\circ} \mathrm{S}$, comprendiendo las provincias de Santa Cruz, Tierra del Fuego y una reducida porción del Chubut en Argentina, y la provincia de Magallanes en Chile. Es un área con un incalculable valor económico y estratégico para la República Argentina. Los importantes depósitos marinos mesozoicos desarrollan al menos tres sistemas petroleros, de los cuales uno es el segundo en importancia del país por el volumen de hidrocarburos entrampados (Zilli et al., 2002).

El estudio de la geología de esta cuenca se ve dificultado por la enorme extensión areal, con las consecuentes variaciones regionales marcadas, moldeadas por eventos que comprenden más de 160 millones de años y espesores sedimentarios que superan los 4.000 metros.

Recién en las últimas décadas, las síntesis realizadas por Leanza (1972), Blasco de Nullo et al. (1980), Riccardi y
Rolleri (1980), Nullo et al. (1981a, 1981b), Malumián et al. (1983), Arbe (1989), Robbiano et al. (1996), Malumián (1999), Nullo et al. (1999), Haller (2002) y Rodríguez y Miller (2005) han permitido comprender aspectos generales de la historia y evolución de esta cuenca, y correlacionar el registro geológico entre sus diferentes sectores.

En el proceso de comprender e interpretar los eventos que configuraron esta compleja cuenca, la estratigrafía, y en especial la bioestratigrafía, son una herramienta fundamental para establecer la edad de las sedimentitas y efectuar correlaciones, tanto entre sus diferentes sectores, como con cuencas vecinas (Malumián et al., 1971; Malumián y Masiuk, 1975, 1976a, 1976b, 1978; Malumián, 1990; Malumián y Nánez, 1990, 1996, 2002; Malumián y Caramés, 1997; Náñez y Malumián, 2008).

Desde el punto de vista bioestratigráfico, los nanofósiles calcáreos son de gran utilidad en el estudio de secuencias 
marinas mesozoicas y cenozoicas. Particularmente en el sector argentino de la Cuenca Austral, los trabajos basados en el estudio de la nanoflora fósil llevados a cabo por Carrizo et al. (1990), Mostajo (1991), Concheyro (1991, 1995), Ronchi y Angelozzi (1994), Concheyro y Angelozzi (2002), Pérez Panera $(2007,2009,2011)$ y Angelozzi et al. (2008), han arrojado resultados prometedores tanto en los aspectos bioestratigráficos como paleoceanográficos.

El objetivo de este estudio es identificar y caracterizar las asociaciones de nanofósiles calcáreos del Cretácico en cinco localidades del sudeste de la Cuenca Austral y evaluarlos en función de su valor bioestratigráfico. En la Figura 1 se ilustra la ubicación geográfica de la Cuenca Austral durante su período de máxima extensión y la ubicación de las localidades estudiadas. Se propone definir las principales asociaciones e identificar especies biomarcadoras a fin de ampliar los recursos bioestratigráficos para la comprensión de la historia geológica de la Cuenca Austral.

\section{ANTECEDENTES}

La primera referencia a nanofósiles calcáreos en la Cuenca Austral se debe a los trabajos de Charrier y Lhasen (1968, 1969), en el sector chileno de la cuenca, en muestras de la Formación Agua Fresca. En estos trabajos se mencionan una asociación de nanofósiles calcáreos que asignaron al Eoceno temprano. Años más tarde Carrizo et al. (1990) estudiaron los microfósiles del Paleógeno de Río Turbio y describieron una asociación de nanofósiles calcáreos muy escasos del Daniano y del Eoceno medio.

Concheyro (1991) estudió los nanofósiles calcáreos de la Formación Man Aike en el pozo SEC-7 al sudeste del Lago Cardiel, e identificó una variada asociación que asignó al Eoceno medio. Mostajo (1991) estudió la secuencia sedimentaria del Pozo Las Violetas 3, al norte de la Isla Grande de Tierra del Fuego e identificó asociaciones de nanofósiles calcáreos del Paleoceno tardío, Eoceno temprano-Eoceno medio y Oligoceno. En los niveles más profundos del pozo, reconoció por primera vez para la cuenca, una asociación del Cretácico Tardío y definió el límite Cretácico/Paleógeno mediando una discontinuidad por ausencia de, al menos, el Paleoceno temprano.

Ronchi y Angelozzi (1994) presentaron un estudio bioestratigráfico de los pozos Campo Boleadoras y Puesto Peter, situados en el centro de la cuenca, en el que definieron las asociaciones de nanofósiles calcáreos y microfósiles calcáreos para el Portlandiano-Valanginiano temprano, Valanginiano-Hauteriviano, Aptiano-Albiano, Coniaciano-Santonia- no, Maastrichtiano temprano, Maastrichtiano tardío, Paleoceno, Eoceno medio tardío y Oligoceno tardío-Mioceno temprano. Sobre la base de estas asociaciones correlacionaron las sedimentitas de las dos localidades e identificaron cuatro discontinuidades: entre el Valanginiano-Hauteriviano y el Aptiano, entre el Aptiano-Albiano y el Coniaciano-Santoniano, entre el Maastrichtiano tardío y el Paleoceno, entre el Paleoceno y el Eoceno medio tardío. En este trabajo se citaron por primera vez para la cuenca los importantes biomarcadores del Cretácico Eprolithus floralis, Axopodorhabdus albianus, Thiersteinia ecclesiastica y Nephrolithus frequens.

Concheyro (1995) analizó la secuencia sedimentaria de los pozos SEC-7, sudeste del Lago Cardiel, YCF. T-136, YCF. Adaro I, YCF. Adaro II, en el área de Río Turbio y Polux x-1, costa afuera. Este trabajo es el antecedente más importante en cuanto al tratamiento sistemático de los nanofósiles calcáreos para esta cuenca. Ilustró y describió sesenta y una especies para el Cretácico y treinta y dos especies para el Paleógeno. Reconoció, a grandes rasgos, dos asociaciones cretácicas y dos paleógenas. A las asociaciones cretácicas les asignó una edad Aptiano?-Cenomaniano temprano y Turoniano-Maastrichtiano. Propuso que durante el Maastrichtiano la Cuenca Austral presentaba una nanoflora característica de la provincia biogeográfica Transicional (sen$s u$ Wind, 1979a) por el predominio de especies con afinidad a latitudes medias.

Concheyro y Angelozzi (2002) realizaron una síntesis sobre el estado del conocimiento de los nanofósiles calcáreos para la Cuenca Austral valiéndose de trabajos previos e informes inéditos de las empresas YPF y GEMA s.r.l. en distintas perforaciones. Caracterizaron las asociaciones del Valanginiano-Hauteriviano, Aptiano-Albiano, Coniaciano-Santoniano, Campaniano, Maastrichtiano, Paleoceno, Eoceno y Oligoceno-Mioceno. Este trabajo constituye un antecedente importante porque resume las características generales de las asociaciones de nanofósiles calcáreos para la cuenca.

Pérez Panera (2007) describió una asociación de nanofósiles calcáreos en el sector sudoriental de la provincia de Santa Cruz, y sobre la base de los biomarcadores recuperados la asignó al Paleoceno temprano. Angelozzi et al. (2008) dieron a conocer las asociaciones de nanofósiles y foraminíferos del Mioceno temprano en varios pozos costa afuera, ubicados entre la Isla Grande de Tierra del Fuego y las Islas Malvinas, e interpretaron un ambiente de plataforma abierta mediaexterna con aguas superficiales templado-frías. Pérez Panera (2009) estudió muestras de recorte de perforación del pozo Cerro Redondo, ubicado en el extremo sudoriental de la 


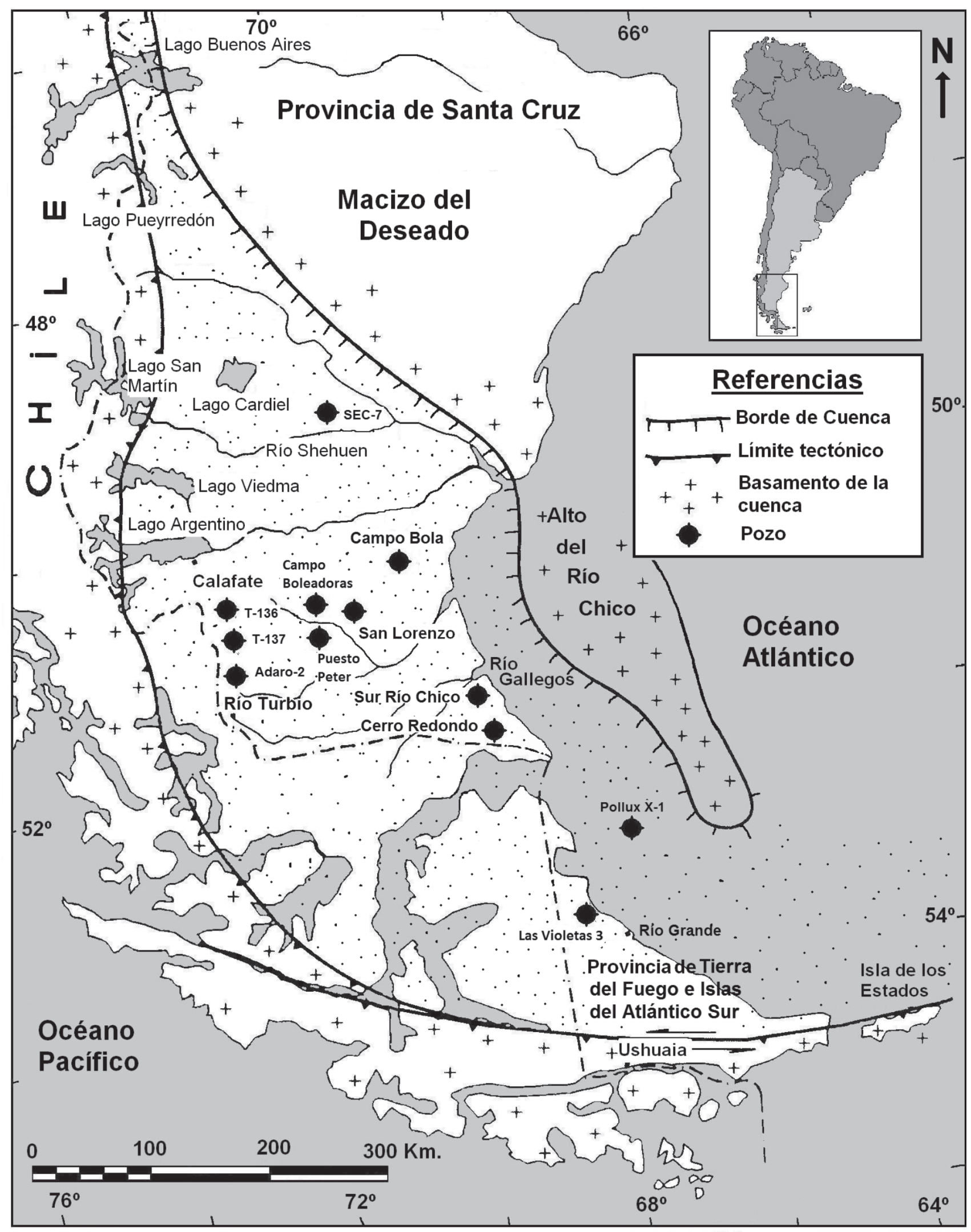

Figura 1. Localización geográfica de la Cuenca Austral durante el período de máxima inundación (Modificado de Nullo et al., 1999) y ubicación de las localidades estudiadas/ Placement of the Austral Basin during its maximum flooding period (modified after Nullo et al., 1999) and location of the studied localities. 
provincia de Santa Cruz y describió varias asociaciones que asignó al Campaniano tardío, al Paleoceno temprano, Eoceno temprano y Eoceno medio. En ese trabajo dedujo la presencia de una discontinuidad entre el Maastrichtiano tardío y el Paleoceno temprano y otra entre el Paleoceno temprano y el Eoceno temprano.

Pérez Panera (2010) describió las características de las asociaciones de nanofóiles calcáreos del Albiano temprano-Albiano medio de la Cuenca Austral y posteriormente, Pérez Panera (2011) evaluó la utilidad del nanofósil Sollasites falklandensis como marcador paleoceanográfico y biostratigráfico para el Albiano de la Cuenca Austral.

\section{MARCO GEOLÓGICO Y PALEONTOLÓGICO}

En el subsuelo del sector oriental de la Cuenca Austral se definen una serie de unidades litoestratigráficas correlacionables con otras que afloran en otros sectores de la cuenca y que se conocen como "unidades tradicionales de subsuelo" (Rodríguez y Miller, 2005). En la Figura 2 pueden visualizarse las equivalencias con las formaciones definidas en los sectores de los lagos Fontana, Pueyrredón, Cardiel, Viedma, Argentino, la zona del valle superior del Río Shehuén, la región de Río Turbio y la Isla Grande de Tierra del Fuego.

El primer ciclo de la secuencia sedimentaria está integrado por las areniscas seleccionadas del Berriasiano-Valanginiano de la Formación Springhill que apoyan en discordancia angular sobre lo que sería el basamento de la cuenca, es decir, los depósitos volcaniclásticos de la Serie Tobífera del Oxfordiano-Tithoniano. En este sector de la cuenca, ciertos niveles de la Serie Tobífera y las areniscas de la Formación Springhill son un importante reservorio de hidrocarburos (Robbiano et al., 1996; Rodríguez y Miller, 2005).

El segundo ciclo sedimentario está representado por la Formación Palermo Aike Inferior y Palermo Aike Medio, equivalentes a la Formación Río Mayer de otros sectores de la cuenca. Esta formación es una importante roca madre de hidrocarburos, constituye un par reservorio-roca madre junto con la subyacente Formación Springhill del Valanginiano tardío-Albiano. El Valanginiano-Hauteriviano está caracterizado por las asociaciones de foraminíferos de Pseudopolymorphina martinezi (Cañón y Ernst) en el Valanginiano y Lenticulina nodosa (Reuss)-Astacolus gibber Epitaliè y Sigal en el Hauteriviano (Malumián y Náńez, 2002). Los nanofósiles calcáreos presentan una asociación dominada por especies del género Watznaueria (Concheyro y Angelozzi, 2002) sin buenos biomarcadores. En el sector sudoriental de la cuenca no se desarrollarían sedimentitas del Barremiano y por encima de los niveles hauterivianos se disponen sedimentitas del Aptiano, caracterizadas por una abundante fauna de radiolarios (Malumián y Nánez, 2002; Concheyro y Angelozzi, 2002). Las sedimentitas del Albiano temprano-Albiano medio se caracterizan por la presencia del foraminífero Globigerinelloides gyroidinaeformis (Moullade) y para el Albiano tardío Malumián (1990) registró una asociación con Astacolus microdictyotos Epitaliè y Sigal, Marginulina bronnii (Roemer), Lenticulina gaultina (Berthelin), Saracenaria bononiensis (Berthelin), Lingulogavelinella indica Scheibnerova y Valvulineria fueguina Malumián y Masiuk. Concheyro y Angelozzi (2002) describen para el Albiano una asociación de nanofósiles calcáreos caracterizada por Biscutum sp., Broinsonia matalosa (= Vagalapilla matalosa), Chiastozygus litterarius, Cretarhabdus conicus, Eiffellithus turriseiffelii, E. eximius, Eprolithus floralis, Prediscosphaera columnata, Rhagodiscus angustus, $R$. asper, Radiolithus planus, Retecapsa crenulata (= Cretarhabdus crenulatus), $R$. surirella (= Cretarhabdus surirellus) Seribiscutum primitivum, Staurolithites crux (= Zygolithus crux), Stoverius achylosus, Tranolithus phacelosus, Watznaueria barnesiae, y Zeugrhabdotus embergeri.

Durante el tercer ciclo sedimentario en este sector de la cuenca se depositaron las sedimentitas de la Formación Palermo Aike superior asignables al Cenomaniano-Campaniano medio. En este sector de la cuenca no se reconocen asociaciones de foraminíferos para el Cenomaniano-Turoniano (Malumián y Náńez, 2002) como tampoco asociaciones de nanofósiles calcáreos para el Turoniano (Concheyro y Angelozzi, 2002). Malumián y Náńez (2002) lo asociaron al hecho de que durante este período se establecieron facies inadecuadas para el desarrollo de microfaunas en relación a una etapa regresiva cenomaniana. Los nanofósiles calcáreos Chiastozygus litterarius, Eiffellithus turriseiffelli, Prediscosphaera columnata, Rhagodiscus angustus, $R$. asper, Seribiscutum primitivum y Tranolithus phacelosus caracterizan las asociaciones del Cenomaniano, y Staurolithites crux (= Zygolithus crux), Corollithion cf. C. exiguum, Calculites obscurus y Thiersteinia ecclesiastica a las poco diversas asociaciones del ConiacianoSantoniano (Concheyro y Angelozzi, 2002).

El cuarto ciclo sedimentario para este sector de la cuenca está integrado por la Formación Magallanes inferior (pars.), campaniana tardía en su base, extendiéndose hasta el Daniano donde se comprueba una discordancia erosiva (Biddle et al., 1986; Malumián, 2002; Pérez Panera, 2009). Las sedimentitas del ?Campaniano tardío-Maastrichtiano temprano son portadoras de una asociación de "SpiroplectamminaTextularia," asociación de foraminíferos aglutinados típica 
de ambientes hiposalinos (Malumián y Náñez, 2002). Sobre la base de esta asociación Flores et al. (1973) definen informalmente una "zona de foraminíferos arenáceos" que posteriormente Malumián y Masiuk (1976a, 1978) asignan al Maastrichtiano temprano con dudas. Esta misma asociación la registraron Náńez y Malumián (2008) en el pozo SC-1, al sudeste de la provincia de Santa Cruz, y la asignaron al Maastrichtiano. En niveles superiores, las sedimentitas del Maastrichtiano portan la asociación de Coryphostoma incrassata gigantea (Wicher) que se caracteriza por formas calcáreas, en su mayoría bulimináceos de hábito infaunal. En cuanto a los nanofósiles calcáreos, las sedimentitas del Campaniano están caracterizadas por una asociación dominada por Reinhardtites anthophorus, Prediscosphaera columnata, Eiffellithus turriseiffelii, Gartnerago obliquum, Braarudosphaera bigelowii y Micula staurophora y las del Maastrichtiano por Ahmuellerella octoradiata, Arkhangelskiella cymbiformis, Chiastozygus garrisonii, Eiffellithus turriseiffelii, Markalius inversus, Braarudosphaera bigelowii, Cribrosphaerella ehrenbergii, C. daniae, Micula staurophora (= Micula decussata), Micula concava, Prediscosphaera spinosa y Nephrolithus frequens (Concheyro y Angelozzi, 2002). Pérez Panera (2009) registró en muestras de recorte de perforación en la localidad de Cerro Redondo una asociación de nanofósiles calcáreos dominada por las especies Reinhardtites anthophorus, Kamptnerius magnificus, Chiastozygus garrisonii, Prediscosphaera cretacea, Staurolithites zoensis, Repagulum parvidentatum, Biscutum coronum, Ahmuellerella octoradiata, Calculites obscurus y Cribrosphaerella ehrenbergii, que asigna al Campaniano tardío. Por encima de los niveles portadores de los nanofósiles del Campaniano tardío reconoce la asociación de foraminíferos aglutinados y por posición estratigráfica interpreta esos niveles como Maastrichtiano temprano. Feruglio (1949) citó la presencia de Hoplitoplacenticeras plasticum Paulcke en una perforación en Punta Norte, cerca de Puerto Coig y Rossi de García y Camacho (1965) un Eubaculites? sp. en la perforación SC3, que de acuerdo con Riccardi (2002) corresponderían al Campaniano tardío y Maastrichtiano respectivamente.

\section{MATERIALES Y MÉTODOS}

Se estudiaron 377 muestras de recorte de perforación previamente lavadas provenientes de cinco pozos de exploración cedidos por la empresa Petrobras-Energía S.A. que representan dos transectas en el sector sudoriental del sector argentino de la Cuenca Austral. La primera de orientación sud-sudeste-nor-noroeste que según este orden queda conformado por los pozos Cerro Redondo, Sur Río Chico,
Cañadón Salto y Campo Bola. La quinta localidad, el pozo San Lorenzo, configura la segunda transecta, que se dispone en sentido sureste-noroeste con respecto a la localidad de Cerro Redondo. En la Figura 1 se indica la ubicación de las localidades. Todas las muestras estudiadas en este trabajo corresponden a niveles del Cretácico. En cada caso se realizó un preparado para su observación bajo microscopio óptico y de cada muestra se conservó material a fin de que puedan repetirse las preparaciones.

Los preparados de las muestras se identifican con las iniciales del nombre del pozo y un número que indica la profundidad bajo boca de pozo. Los mismos se encuentran depositados en la colección del Departamento de Geología de la Facultad de Ciencias Exactas y Naturales de la Universidad Nacional de Buenos Aires, bajo las siglas BAFC-NP y los números 3434 a 3482 (Cerro Redondo); 3643 a 3732 (Sur Río Chico); 3483 a 3537 (Cañadón Salto); 3405 a 3427 (Campo Bola); 3538 a 3557 (San Lorenzo). En los cuadros de distribución (Archivos Complementarios 1-5) puede observarse el número de repositorio que corresponde a cada localidad y la profundidad.

La técnica utilizada para la realización de los preparados al microscopio óptico es la de decantación por gravedad (Gardet, 1955; Bramlette y Sullivan, 1961). Siguiendo el criterio de Concheyro (1995), en cada caso se tomó dos gramos de sedimento y se molió en un mortero de bronce hasta lograr una textura similar al talco. Posteriormente, la mitad del sedimento molido se pasó a frascos de vidrio de $10 \mathrm{ml}$ previamente lavados con una solución débil (aprox. 1 \%) de ácido clorhídrico y abundante agua potable, y la otra mitad se guardó en bolsas de nylon etiquetadas. Se agregó agua destilada y se agitó la mezcla. El frasco con el sedimento disuelto en el agua fue expuesto a 30 segundos de lavado con ultrasonido y se dejó reposar la solución por dos minutos, transcurridos éstos se pipeteó con sorbetes descartables dos gotas del sobrenadante. Estas gotas fueron dispersadas en un cubreobjetos y llevadas a una plancha calefactora, a unos $60-70^{\circ}$. Una vez seca la gota sobre el cubreobjetos, se colocaron entre dos y tres gotas de bálsamo de Canadá sintético y se selló sobre un portaobjetos. Sólo para las muestras del pozo San Lorenzo se utilizó el cemento de contacto Norland Optical Adhesive 61 en lugar de bálsamo de Canadá sintético.

Los preparados se analizaron con un microscopio biológico con contraste de fases y luz polarizada a un aumento X1200 y con un microscopio petrográfico con contraste de fases, luz polarizada, lámina de yeso y platina giratoria a un aumento X1000 de los laboratorios de la Consultora 
Bioestratigráfica GEMA S.R.L. Las fotografías de microscopio óptico fueron obtenidas en ese mismo laboratorio con una cámara digital Sony modelo Cyber-shot DSCP10 de 5.1 megapíxeles. Algunas pocas fotografías fueron tomadas en un microscopio petrográfico marca Leica del Laboratorio de Bioestratigrafía de Alta Resolución, Departamento de Ciencias Geológicas, Universidad Nacional de Buenos Aires, con un equipamiento fotográfico similar.

Durante la observación de los preparados se empleó una metodología cuantitativa, registrando para cada muestra un total de al menos 300 individuos cuando fue posible. Este esfuerzo de muestreo representa una confianza del $95 \%$ de hallar un individuo con una abundancia específica del $1 \%$ en la asociación (Thierstein et al., 1977). En cada caso también se registró un conteo de campos observados y a partir de la relación individuos/campos observados se calculó un índice de abundancia para cada muestra. Estos datos se volcaron en una carta de distribución muestra/especies para cada localidad, (Archivos Complementarios 1-5), donde además constan, para cada muestra, la riqueza específica y el estado de preservación. El criterio que se empleó para cuantificar el estado de preservación es el de Roth y Thierstein (1972). Este criterio se basa en una escala subjetiva que cuantifica el grado de sobrecrecimiento de los cristales de carbonato de calcio de los nanofósiles desde un grado O-3 que es un sobrecrecimiento muy importante, donde la especie o género de nanofósil no puede ser reconocido, hasta un grado O-1 donde el sobrecrecimiento es muy moderado, pasando por un estado de preservación excelente $\mathrm{X}$, hasta tres niveles de grados de disolución, donde E-1 responde a una disolución moderada y E-3 a una disolución extrema en que deja de reconocerse la especie o el género del nanofósil. Cuando se encontraron especímenes en muy mal estado de preservación y de diagnosis dudosa no se tomaron en cuenta en la interpretación bioestratigráfica a fin de minimizar el error por malas determinaciones; aunque se apuntaron, fueron excluidos del análisis y las cartas de distribución.

Durante la interpretación bioestratigráfica se contó con

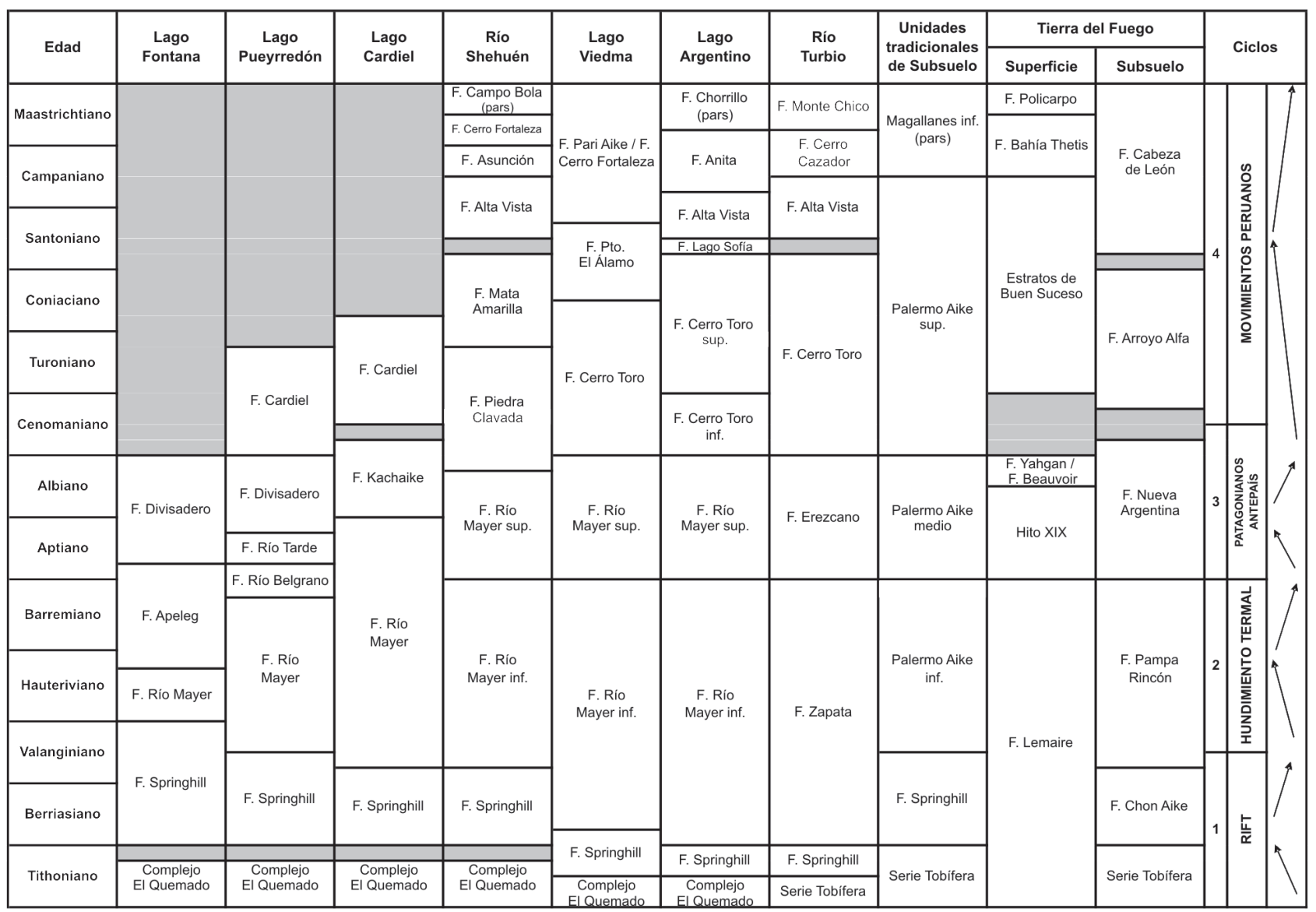

Figura 2. Relaciones estratigráficas entre las unidades litoestratigráficas de los diferentes sectores de la Cuenca Austral y su relación a los ciclos tectosedimentarios mayores. (Modificado de Nullo et al., 1999 y Rodríguez y Miller, 2005)/ Stratigraphic relations between litostratigraphic units in different sectors of the Austral Basin and their relation with the main tecto-sedimentary cycles. (Modified after Nullo et al., 1999 and Rodríguez and Miller, 2005). 
el control de otros microfósiles (foraminíferos, ostrácodos y radiolarios), estudiados por Diana Ronchi (GEMA S.R.L.) (comunicación personal, Ronchi, 2007, 2008, 2009). De acuerdo con Malumián (1970) y Gartner (1977), como se trata de muestras de recorte de perforación, se seleccionaron como biohorizontes los bioeventos de última aparición estratigráfica. Estos bioeventos fueron comparados con las biozonaciones basadas en nanofósiles calcáreos en áreas próximas, en especial con las biozonaciones de Wise $(1983,1988)$ para el Plateau de Malvinas y la de Watkins et al., (1996) para los mares australes.

\section{BIOESTRATIGRAFÍA}

Se presentan los principales bioeventos nanofosilíferos que se reconocieron en cada una de las localidades estudiadas. A partir del análisis de las muestras se definen una serie de tramos, que se individualizan en el sentido normal de la perforación. El criterio de segregación de los tramos responde a la identificación de los nanoeventos más importantes reconocidos, a la caracterización de posibles discontinuidades y al aislamiento de secciones estériles en cuanto a los nanofósiles calcáreos. La interpretación bioestratigráfica para cada una de las localidades se resume en las Figuras 3-7.

A efectos de hacer más fluida la lectura se utilizan las abreviaturas LAD (last appearance datum) para la última aparición estratigráfica de un taxón, FAD (first appearance datum) para la primera aparición estratigráfica y mbbp como abreviatura de metros bajo boca de pozo.

\section{Cerro Redondo (ver Fig. 3)}

Desde 1025-1050 hasta 1891-1900 mbbp (51 muestras).

Primer tramo. 1025-1050 / 1050-1075 mbbp (2 muestras), Maastrichtiano temprano. Este tramo resultó estéril desde el punto de vista de los nanofósiles calcáreos. Sin embargo, se prepararon muestras para el análisis de otros microfósiles calcáreos y se recuperó una asociación de foraminíferos aglutinados, caracterizada por Trochammina texana Cushman y Waters, Haplophragmoides walteri (Grzybowski) y "Spiroplectammina-Textularia" sp. Malumián, que lo asignarían al Maastrichtiano temprano.

Segundo tramo. 1075-1100 / 1100-1150 mbbp (2 muestras), Campaniano. En este tramo se reconoció una asociación típicamente cretácica tardía, con una alta diversidad. Las especies más importantes desde el punto de vista bioestratigráfico son Biscutum coronum, B. magnum, Broinsonia signata, Eiffellithus eximius, Reinhardtites anthophorus y $R$. levis, entre otros. De acuerdo al biomarcador $R$. anthophorus, cuyo LAD se registró a los 1075-1100 mbbp se asigna a este tramo una edad no más reciente que Campaniano tardío, zona CC22 de Sissingh (1977). En la biozonación de Wise (1988) este bioevento se solapa con la zona de Biscutum coronum, limitado en su techo por el LAD de Biscutum coronum, que también se registró aquí a la misma profundidad. De acuerdo con la presencia de Reinhardtites levis en las dos muestras que integran este tramo, podría limitarse el mismo al Campaniano tardío, ya que en los mares australes el FAD de este biomarcador ocurre dentro del Campaniano tardío (Watkins et al., 1996). Sin embargo es posible que el individuo recuperado en la muestra más profunda esté contaminado o incluso es posible que dentro de los 50 metros que esta muestra involucra esté también contenido el Campaniano temprano. Por estas razones, y teniendo en cuenta la edad asignada al tramo subyacente, se considera el tramo en su conjunto como Campaniano.

Tercer tramo. 1150-1200 mbbp (1 muestra), ConiacianoSantoniano. Este tramo está representado por una sola muestra en la que se registró el LAD del biomarcador Eprolithus floralis, bioevento que indica el techo de la zona de Eprolithus floralis (= Lithastrinus floralis) de Wise (1988), ConiacianoSantoniano, y una edad no más reciente que Santoniano según el esquema de Watkins et al. (1996). En consecuencia, este bioevento se correlaciona con el techo de la zona CC16 de la biozonación de Sissingh (1977) y considerando la posición estratigráfica, el espesor sedimentario involucrado y la asociación en general, se le asigna una edad ConiacianoSantoniano.

Cuarto tramo. 1200-1250 / 1550-1560 mbbp (14 muestras), Albiano tardío-Cenomaniano. A los 1200-1250 mbbp se registró el LAD de Axopodorhabdus albianus, bioevento que en diferentes biozonaciones para Europa y el Océano Índico (i.e. Bralower et al., 1995; Burnett, 1999) se correlaciona dentro de la zona CC10 de Sissingh (1977), Cenomaniano tardío, permitiendo asignarle al tramo una edad no más reciente que Cenomaniano. En ese nivel se observó también el LAD de la especie Radiolithus planus, que aunque no es utilizado como biomarcador, su biocrón no se extiende más allá del Cenomaniano (Varol, 1992), lo que confirmaría esta asignación. De acuerdo a la posición estratigráfica del tramo, las características de la asociación en general y en particular a la importante presencia de Seribiscutum primitivum, se interpreta como Albiano tardío-Cenomaniano.

Quinto tramo. 1560-1570 / 1640-1650 mbbp (9 muestras), Aptiano-Albiano medio. A los 1560-1570 mbbp se observó el LAD de Sollasites falklandensis, bioevento que 
marca el techo de la subzona de Repagulum parvidentatum de la zona de Tranolithus orionatus en la biozonación de Wise (1988), Albiano temprano-Albiano medio. Esta zona se correlaciona con la zona CC8 de la biozonación de Sissingh (1977). A los 1640-1650 mbbp se observó el LAD de Micrantholithus hoschulzii, que no supera el Aptiano (Sissingh, 1977; Wise, 1983; Bown et al., 1999). Este bioevento estaría evidenciando una asociación de edad aptiana al final del tramo, que se correlaciona con la zona CC7 del esquema de Sissingh (1977). En su conjunto el tramo sería equivalente a las zonas CC7-CC8.

Sexto tramo. 1650-1660 / 1729-1738 mbbp (6 muestras), Valanginiano tardío-Hauteriviano temprano. La asociación nanofosilífera recuperada de este tramo presenta características similares a las del tramo inmediato superior, interpretán-

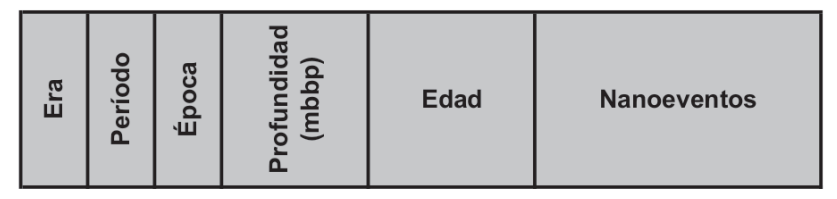

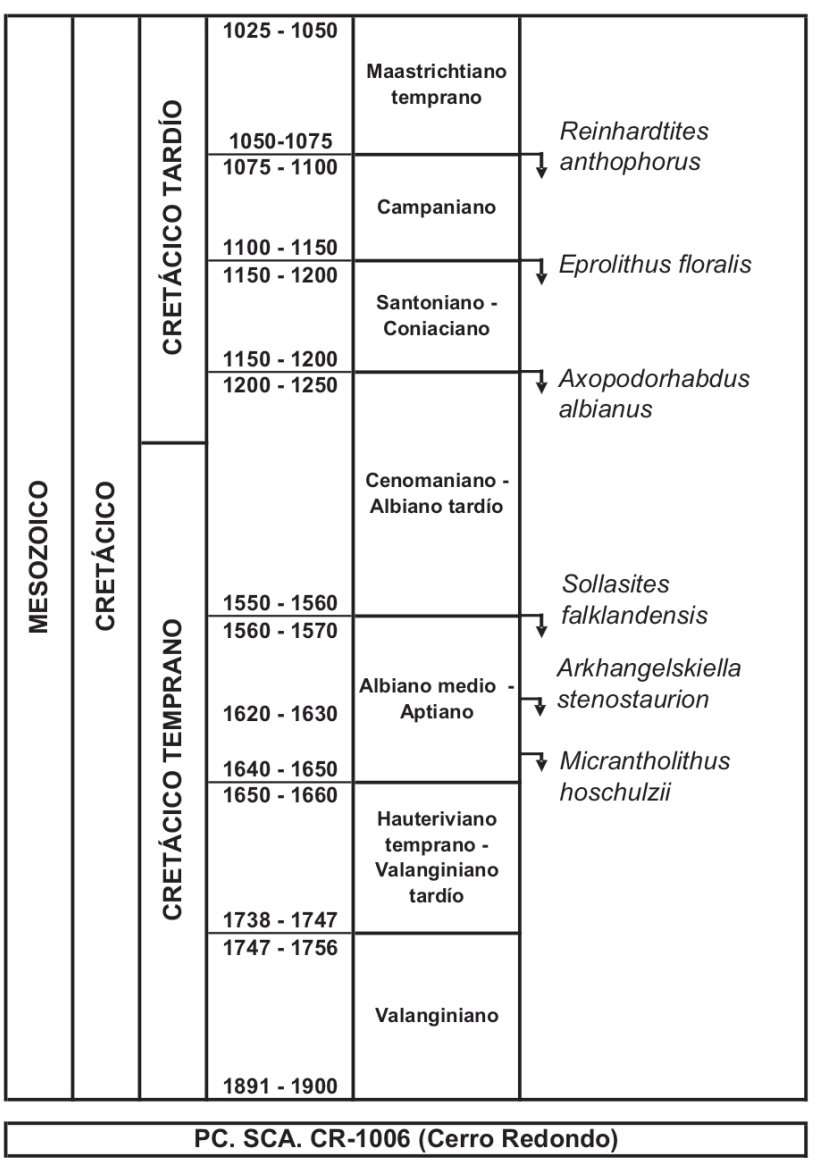

Figura 3. Bioestratigrafía y principales nanoeventos en el pozo Cerro Redondo/ Biostratigraphy and main calcareous nannofossils bioevents at Cerro Redondo borehole. dose que la misma sería producto de la contaminación del material por los trabajos de perforación, por lo tanto es posible que estos niveles sean realmente muy pobres o estériles. La asignación de edad se basa exclusivamente en el estudio de los foraminíferos asociados. A los 1650-1660 mbbp se recuperaron los foraminíferos Lenticulina nodosa (Reuss) y Astacolus gibber Espitaliè y Sigal, especies que definen la zona informal de "Lenticulina nodosa-Astacolus gibber" para Cuenca Austral, de edad Valanginiano tardío-Hauteriviano temprano (Masiuk y Ronchi, 1981; Malumián y Nánez, 2002). Séptimo tramo. 1738-1747 / 1891-1900 mbbp (17 muestras), Valanginiano. Este tramo presenta las mismas características que el sexto tramo, una intensa contaminación por material caído y ausencia de nanofósiles calcáreos biomarcadores que precisen la edad de la asociación. La edad asignada a este tramo se basa exclusivamente en su contenido en foraminíferos. A los 1738-1747 mbbp se recuperó el foraminífero Pseudopolymorphina martinezi (Cañón y Ernst) y esta especie define la zona informal de "Pseudopolymorphina martinezi" de edad valanginiana (Masiuk y Ronchi, 1981; Malumián y Náñez, 2002).

\section{Sur Río Chico (ver Fig. 4)}

Desde 990-995 hasta 1618-1620 mbbp (150 muestras).

Primer tramo. 990-995 / 1003-1005 mbbp (4 muestras), Maastrichtiano tardío. A los 990-995 mbbp se registraron los LAD de Arkhangelskiella cymbiformis, A. maastrichtiana, Kamptnerius magnificus, Micula concava, M. staurophora, Neprolithus frequens y Prediscosphaera stoveri entre otras especies de nanofósiles característicos del Cretácico Tardío. Estas especies no sobreviven la extinción de fines del Cretácico y permiten definir el límite Cretácico/Paleógeno a la profundidad de 990 mbbp, por encima de la cual se observaron nanofósiles danianos. El biomarcador Nephrolithus frequens se recuperó a lo largo de todo el tramo y en consecuencia se asigna, más precisamente, a la zona de Neprolithus frequens miniporus de Watkins et al. (1996), última zona del Maastrichtiano.

Segundo tramo. 1005-1010 / 1075-1080 mbbp (15 muestras), Maastrichtiano temprano. Este tramo resultó estéril desde el punto de vista de los nanofósiles calcáreos. Sin embargo se recuperó una asociación de foraminíferos aglutinados, caracterizada por Haplophragmoides walteri (Grzybowski) y "Spiroplectammina-Textularia" sp. Malumián, que permitirían asignar este nivel al Maastrichtiano temprano.

Tercer tramo. 1080-1085 / 1090-1095 mbbp (3 muestras), ?Santoniano-Campaniano. La asociación recuperada en este 
tramo permitió asignarlo al Santoniano-Campaniano tardío sobre la base del LAD del biomarcador Reinhardtites anthophorus, que indica una edad no más reciente que Campaniano tardío, zona CC22 de Sissingh (1977). No se reconocen otros biomarcadores que permitan subdividir el tramo y la edad santoniana se presume por la posición estratigráfica.

Cuarto tramo. 1095-1100 / 1150-1155 mbbp (12 muestras), Coniaciano-Santoniano temprano. En el techo de este tramo se observó el LAD del biomarcador Thiersteinia ecclesiastica, que de acuerdo con Wise (1988) marca el tope de la zona de Thiersteinia ecclesiastica (Coniaciano-Santoniano temprano) equivalente a las zonas CC13 y CC14 de Sissingh (1977). La asociación acompañante en su conjunto coincide con una edad Coniaciano-Santoniano, confirmado por el LAD de Eprolithus foralis a los 1115-1120 mbbp, pero resulta imposible asignarle una edad precisa a la asociación en la base del tramo.

Quinto tramo. 1155-1160 / 1285-1290 mbbp (27 muestras), Albiano tardío-Cenomaniano. A los 1155-1160 mbbp se registró el LAD del biomarcador Axopodorhabdus albianus, bioevento que se correlaciona dentro de la zona CC10 de Sissingh (1977), Cenomaniano. A lo largo de este tramo se recuperaron además otras especies que si bien no son diagnósticas, son características del Albiano, como Axopodorhabdus dietzmanii, Prediscosphaera columnata, Zeugrhabdotus scutula y $Z$. trivectis entre otros. El LAD de Eiffellithus monechiae, especie que no supera el Albiano tardío (Shamrock y Watkins, 2009), registrado a los 1185-1190 mbbp estaría indicando el límite Albiano-Cenomaniano.

Sexto tramo. 1290-1295 / 1425-1430 mbbp (28 muestras), Albiano temprano-Albiano medio. En el techo del tramo se observó el LAD de Sollasites falklandensis, bioevento que marca el techo de la subzona de Repagulum parvidentatum de Wise (1988) y se correlaciona con el techo de la zona CC8 de Sissingh (1977). A los 1350-1355 mbbp se registró el LAD de Grantarhabdus meddii y si bien esta especie no es utilizada como biomarcador en otras biozonaciones, en este trabajo se la encuentra muchas veces asociada al LAD de Sollasites falklandensis y ha resultado útil para confirmar el Albiano temprano-Albiano medio.

Séptimo tramo. 1430-1435 / 1483-1486 mbbp (16 muestras), Aptiano. En este tramo las asociaciones de nanofósiles recuperados presentan las características de una edad albiana temprana a media, pero el análisis de los microfósiles sugiere Aptiano, de acuerdo al aumento y dominio casi exclusivo de radiolarios (Flores et al., 1973; Malumián y Náńez, 2002; Concheyro y Angelozzi, 2002). En consecuencia se interpre- ta que existe una importante contaminación desde los niveles suprayacentes y se le asigna una edad Aptiano. A partir de los 1430-1435 mbbp el índice de abundancia disminuye drásticamente y esos valores confirmarían que estos niveles presentan muy pocos o ningún nanofósil autóctono.

Octavo tramo. 1486-1489 / 1492-1495 mbbp (3 muestras), Valanginiano tardío-Hauteriviano temprano. Este tramo se considera estéril desde el punto de vista de los nanofósiles calcáreos. Los niveles donde se recuperaron algunas especies se consideran estériles ya que probablemente corresponden a especímenes caídos de niveles superiores. Los foraminíferos recuperados permiten asignarle una edad Valanginiano tardío-Hauteriviano temprano por la presencia de Lenticulina nodosa (Reuss) y Astacolus gibber Espitaliè y Sigal, especies que definen la zona informal de Lenticulina nodosaAstacolus gibber para la Cuenca Austral (Masiuk y Ronchi, 1981; Malumián y Náńez, 2002).

Noveno tramo. 1495-1498 / 1618-1620 mbbp (42 muestras), estéril. Este tramo resultó estéril en cuanto a los nanofósiles calcáreos y los microfósiles. En algunos niveles se recuperaron microfósiles, pero se interpreta que son consecuencia de contaminación a partir de niveles suprayacentes.

\section{Cañadón Salto (ver Fig. 5)}

Desde 1135 hasta $1358-1361$ mbbp (58 muestras).

Primer Tramo. 1135 / 1181-1191 mbbp (7 muestras), Albiano tardío-Cenomaniano. En este tramo se registra la especie biomarcadora Axopodorhabdus albianus, junto a otras como Arkhangelskiella stenostaurion, Crucibiscutum salebrosum y Seribiscutum primitivum lo que permite asignarle una edad Albiano tardío-Cenomaniano, zonas CC9-CC10 de Sissingh (1977). A los 1172-1181 mbbp se registra el LAD de Eiffellithus monechiae, especie que no supera el Albiano tardío (Shamrock y Watkins, 2009) y permitiría establecer el límite Albiano-Cenomaniano.

Segundo tramo. 1191-1200/1350-1352 mbbp (48 muestras), Albiano temprano-Albiano medio. A los 1191-1200 mbbp se registró el LAD del biomarcador Sollasites falklandensis. Sobre la base de este bioevento se asigna el tramo al Albiano temprano-Albiano medio, zona CC8 de Sissingh (1977) subzonas de Sollasites falklandensis y Repagulum parvidentatum de Wise (1988).

Tercer tramo. 1352-1355 / 1358-1361 mbbp (3 muestras), estéril. Este tramo resultó estéril desde el punto de vista de los nanofósiles calcáreos. Se recuperaron algunos pocos microfósiles calcáreos, como Lingulogavelinella indica Scheibnerova, Saracenaria bononiensis (Berthelin) y Valvulineria fueguina 
Malumián y Masiuk entre otros, que indicarían una edad Albiana, pero se considera que proceden de contaminación desde niveles suprayacentes debido a su pobre abundancia en relación al tramo anterior.

Campo Bola (ver Fig. 6)

Desde 1225-1230 hasta 1518-1520 mbbp (98 muestras).

Primer tramo. 1225-1230 / 1265-1270 mbbp (9 muestras), Maastrichtiano temprano. Las muestras involucradas

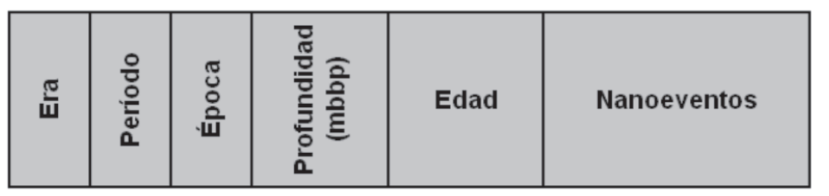

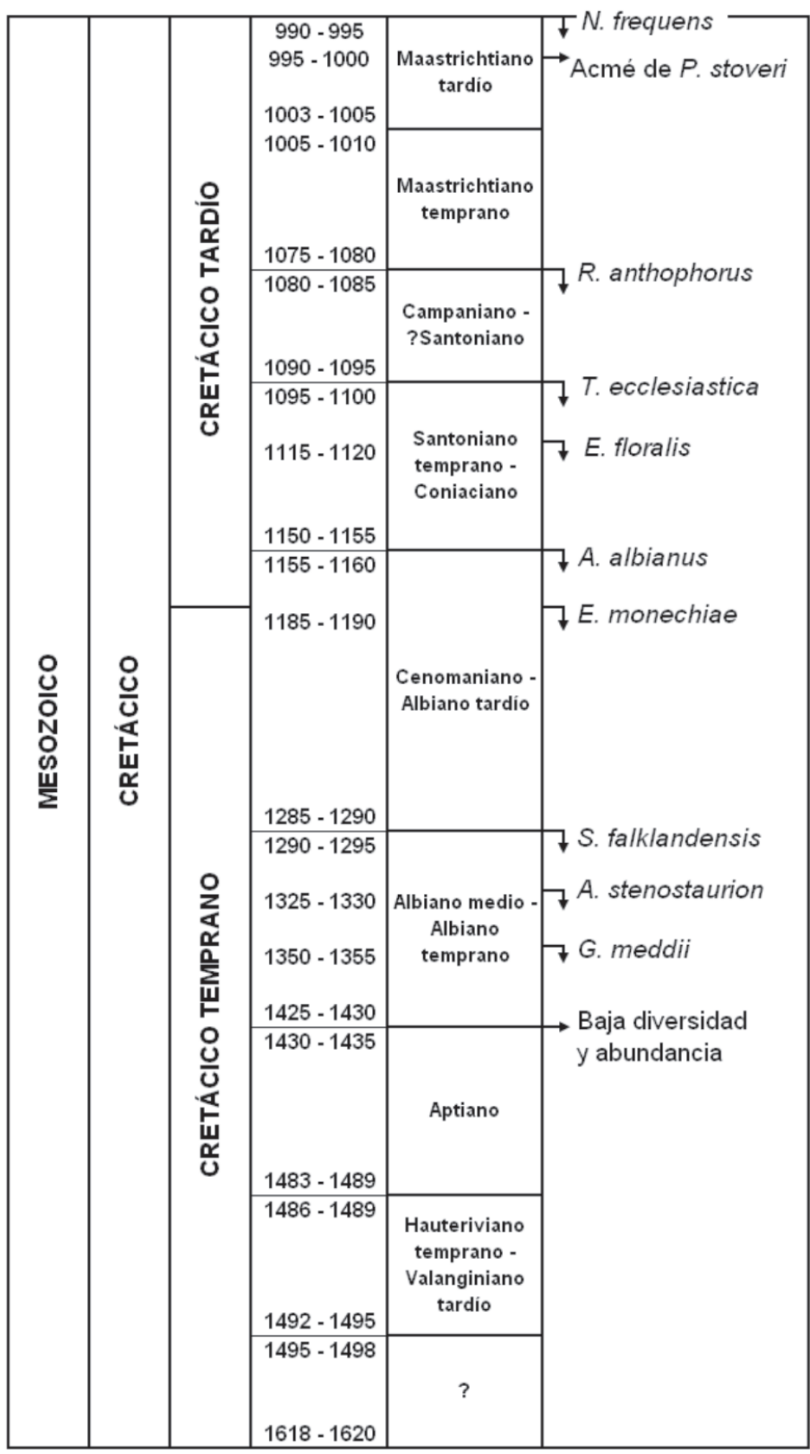

PC. SCA. SRC-9 (Sur Río Chico)

Figura 4. Bioestratigrafía y principales nanoeventos en el pozo Sur Río Chico/ Biostratigraphy and main calcareous nannofossils bioevents at Sur Río Chico borehole. en este tramo resultaron estériles desde el punto de vista de los nanofósiles calcáreos. Sin embargo se recuperó una asociación de foraminíferos aglutinados, dominada por especies del género Haplophragmoides Cushman, que asignarían este nivel al Maastrichtiano temprano.

Segundo tramo. 1270-1275 / 1305-1310 mbbp (8 muestras), Coniaciano/Santoniano-Campaniano. A los 12701275 mbbp se recuperó una pobre asociación de afinidad cretácica tardía. Con ella el LAD del biomarcador Reinhardtites anthophorus sitúa esta asociación en una edad no más reciente que Campaniano tardío, zona CC22 de Sissingh (1977). Los niveles comprendidos entre las profundidades 1275-1280 y 1305-1310 resultaron estériles desde el punto de vista de los nanofósiles calcáreos, pero se recuperaron foraminíferos que permiten interpretar todo el tramo como Coniaciano/Santoniano-Campaniano.

Tercer tramo. 1310-1315 / 1370-1375 mbbp (13 muestras), Albiano tardío. En este tramo se recuperó una asociación de nanofósiles calcáreos del Albiano tardío pero sin que se puedan observar eventos bioestratigráficos significativos. En consecuencia, el límite superior del tramo se establece a partir de los foraminíferos (véase Malumián y Náńez, 2002), principalmente por las especies Lenticulina gaultina (Berthelin), Lenticulina secans (Reuss), Epistomina chapmani Dam,
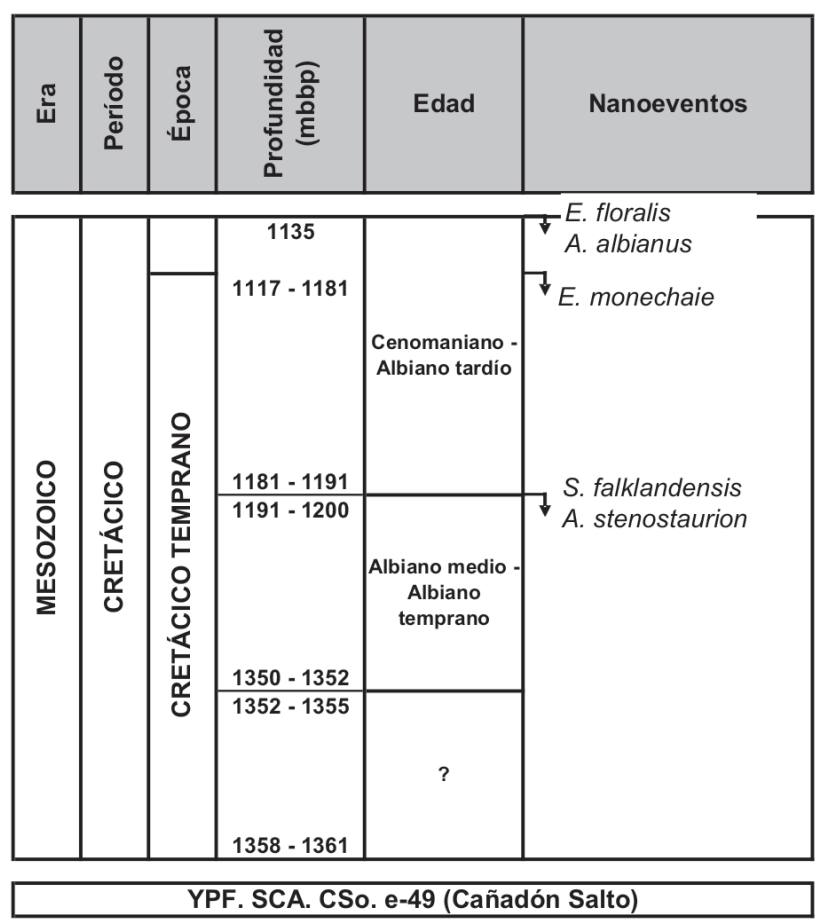

Figura 5. Bioestratigrafía y principales nanoeventos en el pozo Cañadón Salto/ Biostratigraphy and main calcareous nannofossils bioevents at Cañadón Salto borehole. 
Saracenaria triangularis (d'Orbigny), Saracenaria bononiensis (Berthelin), y el ostrácodo Majungaella santacruziana (Rossi de García), que de acuerdo a Ballent et al. (1998) no supera el Albiano en la Cuenca Austral.

Cuarto tramo. 1375-1380 / 1406-1408 mbbp. Albiano temprano-Albiano medio. A los 1375-1380 mbbp se registró el LAD de Sollasites falklandensis, lo que marca el techo de la subzona de Repagulum parvidentatum de Wise (1988), de edad Albiano medio. Otras especies que integran la asociación cuyos biocrones no superan el Cretácico Temprano, como Crucibiscutum hayi y Sollasites horticus; permiten confirmar una asignación de edad Albiano temprano-Albiano medio para todo el tramo, zona CC8 de la biozonación de Sissingh (1977).

Quito tramo. 1408-1409 / 1518-1520 mbbp (57 muestras), estéril. En este tramo todas las muestras resultaron estériles en nanofósiles y microfósiles calcáreos.

\section{San Lorenzo (ver Fig. 7)}

Desde 2762-2764 hasta 2818-2820 mbbp (20 muestras).

Primer Tramo. 2762-2764 / 2788-2791 mbbp (10 muestras), Valanginiano tardío-Hauteriviano temprano. En el
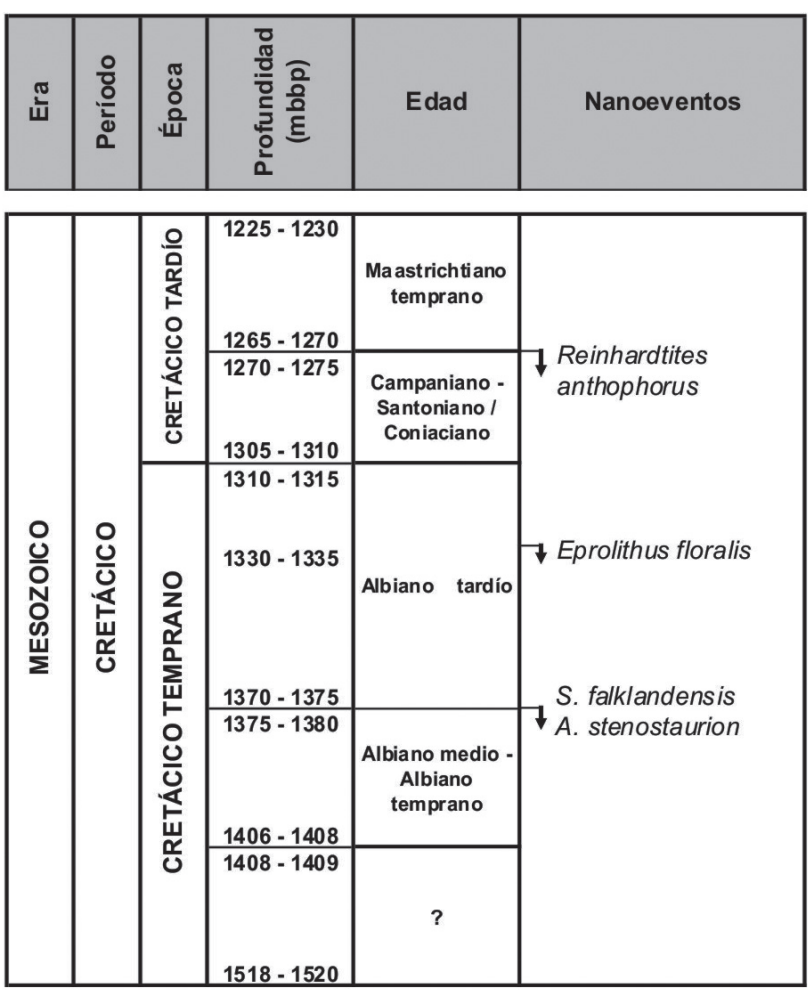

PC. SCl. SCA. CB-1001 (Campo Bola)

Figura 6. Bioestratigrafía y principales nanoeventos en el pozo Campo Bola/ Biostratigraphy and main calcareous nannofossils bioevents at Campo Bola borehole. primer tramo se recuperaron nanofósiles calcáreos considerados en gran medida caídos de niveles superiores y la asociación autóctona estaría muy pobremente representada o incluso algunos niveles podrían ser realmente estériles. $\mathrm{Si}$ bien la microfauna asociada muestra también un alto grado de contaminación desde niveles superiores, se asigna al Valanginiano tardío-Hauteriviano temprano porque se recuperaron los foraminíferos Lenticulina nodosa (Reuss), Lenticulina crepidularis (Roemer), Astacolus gibber Epitaliè y Sigal y Saracenaria forticosta (Bettenstaedt). Esta asociación de microfósiles permite asignar el tramo a la zona informal de Lenticulina nodosa-Astacolus gibber de la Cuenca Austral (Masiuk y Ronchi, 1981; Malumián y Náñez, 2002).

Segundo Tramo. 2791-2794 / 2818-2820 mbbp (10 muestras), Valanginiano. Este tramo se asigna al Valanginiano de acuerdo al contenido de los foraminíferos Pseudopolymorphina martinezi (Cañón y Ernst), Lenticulina nodosa (Reuss), Planularia madagascariensis Espitaliè y Sigal, Astacolus gibber Espitaliè y Sigal y Eoguttulina sp. cf. E. anglica Cushman y Ozawa. Esto permite asignar el tramo a la zona informal de Pseudopolymorphina martinezi de la Cuenca Austral (Masiuk y Ronchi, 1981; Malumián y Náñez, 2002). Los nanofósiles observados en este tramo sugieren una contaminación importante desde niveles estratigráficamente superiores aunque a los 2797-2800 mbbp se registró el LAD de Speetonia colligata, biomarcador que no supera el Hauteriviano tardío, límite superior de la zona CC4 de Sissingh (1977). Su abundancia relativa es muy baja y sólo se lo volvió a observar a los 2803-2806 mbbp, por lo que no puede ser considerado para interpretar la edad del tramo. En esta última profundidad se observó también el biomarcador Eiffellithus windii, que en otras cuencas de Argentina tiene su LAD en el Valanginiano tardío, zona CC4 (pars.) de Sissinhg (1977) (Bown y Concheyro, 2004; Lescano y Concheyro, 2009). Estos resultados, a pesar de la pobreza de la nanoflora, confirman la edad interpretada a partir de los foraminíferos asociados.

\section{CRONOESTRATIGRAFÍA Y CORRELACIÓN DE LAS SECUENCIAS ESTUDIADAS}

La secuencia sedimentaria en el sector sudoriental de la Cuenca Austral, particularmente el sector sudeste de la provincia de Santa Cruz, muestra cierta homogeneidad estratigráfica entre las diferentes localidades estudiadas. En las Figuras 8-9 se correlacionan las sedimentitas estudiadas en los pozos de la transecta nor-noroeste-sud-sudeste. En la Figura 10 se esquematiza la interpretación bioestratigráfica y los principales nanoeventos para este sector de la cuenca. 
Las sedimentitas que subyacen a los niveles asignados al Valanginiano resultaron estériles tanto para los nanofósiles como para los microfósiles calcáreos. En consecuencia se asume que poseen una edad no más reciente que Valanginiano. En general estas sedimentitas corresponden a areniscas arcillosas que pasan a wackes y tobas, litologías que permiten explicar la ausencia de microfósiles.

Suprayaciendo se reconocen arcilitas y arcilitas tobáceas en las localidades más orientales y areniscas tobáceas al oeste (i.e. San Lorenzo). La edad de estas sedimentitas fue interpretada como Valanginiano-Hauteriviano temprano a partir de los foraminíferos recuperados, los cuales incluyen importantes biomarcadores como Pseudopolymorphina martinezi (Cañón y Ernst), Lentculina nodosa (Reuss) y Astacolus gibber Epitaliè y Sigal (Masiuk y Ronchi, 1981; Malumián y Nánez, 2002). Los nanofósiles calcáreos hallados en este intervalo están muy pobremente representados o incluso ausentes. Sólo en la localidad de San Lorenzo se observó la presencia de los nanofósiles biomarcadores Speetonia colligata y Eiffellithus windii, que son importantes bioestratigráficamente para las secuencias del Valanginiano-Hauteriviano de la Cuenca Neuquina (Bown y Concheyro, 2004; Hernández et al., 2005; Lescano y Concheyro, 2009). Aunque el hecho de haberlas registrado es un dato importante, su abundancia y continuidad en la secuencia es tan pobre que no es posible realizar interpretaciones bioestratigráficas a partir de ellas.

En ninguna de las localidades estudiadas se recuperaron
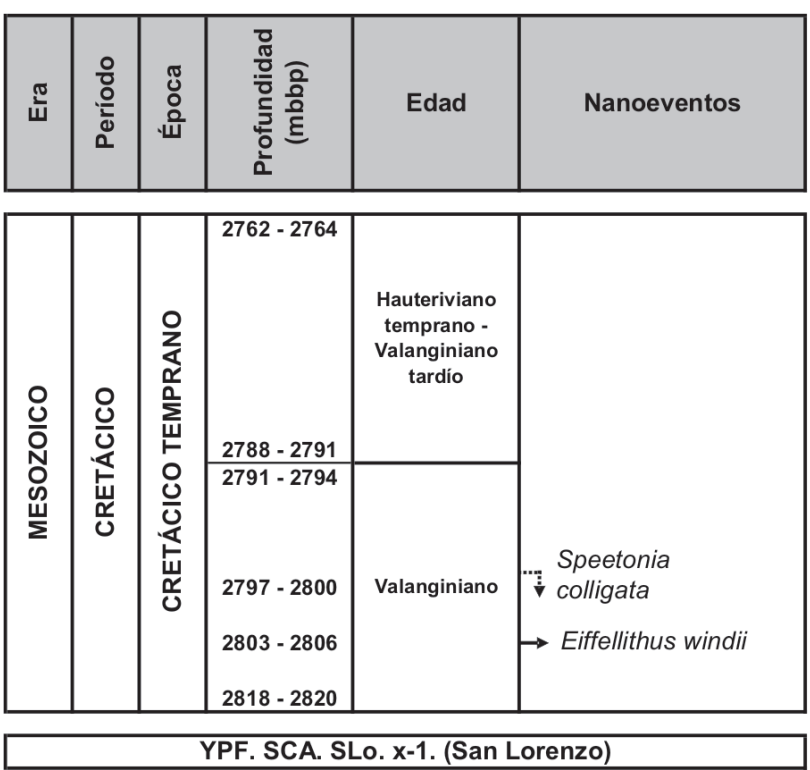

Figura 7. Bioestratigrafía y principales nanoeventos en el pozo San Lorenzo/ Biostratigraphy and main calcareous nannofossils bioevents at San Lorenzo borehole. asociaciones de microfósiles del Hauteriviano tardío y Barremiano sin que medien intervalos estériles entre las sedimentitas anteriormente mencionadas y las suprayacentes, asignadas al Aptiano. Sobre los niveles portadores de la asociación de foraminíferos Lenticulina nodosa-Astacolus gibber de edad Valanginiano tardío-Hauteriviano temprano, se disponen sedimentitas con asociaciones de nanofósiles calcáreos y foraminíferos muy escasos y abundantes radiolarios. Los niveles portadores de radiolarios han sido interpretados como de edad Aptiano en otros sectores de la cuenca (Ronchi y Angelozzi, 1994; Malumián y Nánez, 1996, 2002, Concheyro y Angelozzi, 2002) de manera que estarían faltando las sedimentitas barremianas. El hiato bioestratigráfico que supone una ausencia de sedimentitas asignables al Hauteriviano tardío-Barremiano se interpreta como una discontinuidad. Esta discontinuidad ya había sido identificada anteriormente. Flores et al. (1973) supusieron con dudas una concordancia por ausencia de sedimentitas barremianas entre las formaciones Pampa Rincón y Nueva Argentina en el subsuelo de Tierra del Fuego. Charrier y Malumián (1975) interpretaron un hiato que involucra el Barremiano para el borde oriental de la Cuenca Austral, Ronchi y Angelozzi (1994) interpretaron una discordancia por ausencia de sedimentitas barremianas en dos localidades del centro de Cuenca Austral, y de acuerdo a Concheyro y Angelozzi (2002), en el área comprendida entre los ríos Santa Cruz y Coyle y la costa atlántica, las sedimentitas del Aptiano-Albiano suprayacen en discordancia a las sedimentitas hauterivianas. Sin embargo, cabe aclarar que en la región occidental, zona más próxima al depocentro de cuenca, el Barremiano está representado (Riccardi, 1984, 1988; Kraemer y Riccardi, 1997; AguirreUrreta, 2002).

Las secuencias que se asignan al Aptiano resultaron, en general, estériles, tanto para los nanofósiles como para otros microfósiles calcáreos. En algunas localidades se reconocieron nanofósiles de esta edad (i.e. Micrantholithus hoschulzii en Cerro Redondo) pero en asociaciones muy pobremente representadas y muy contaminadas, lo que no permitió realizar interpretaciones bioestratigráficas fiables. En otras localidades de la Cuenca Austral se recuperó una microfauna muy abundante de radiolarios de supuesta edad aptiana (Flores et al., 1973; Ronchi y Angelozzi, 1994; Concheyro y Angelozzi, 2002). Este acmé de radiolarios se identificó claramente en la localidad de Sur Río Chico, en arcilitas grises con intercalaciones de tobas y arcilitas tobáceas hacia el tope del tramo. En la otra localidad donde se recuperó la asociación de radiolarios, Cerro Redondo, ésta se encuentra 
más o menos amalgamada con los niveles portadores de nanofósiles calcáreos del Albiano temprano-Albiano medio, de manera que no fue posible identificar un límite preciso entre ellas y en consecuencia se interpretan estos niveles como Ap-
tiano-Albiano medio. Estos niveles también están conformados por arcilitas y arcilitas tobáceas, interpretándose las mismas o bien como de facies muy profundas, por debajo de la línea de compensación de la calcita, o bien como registro

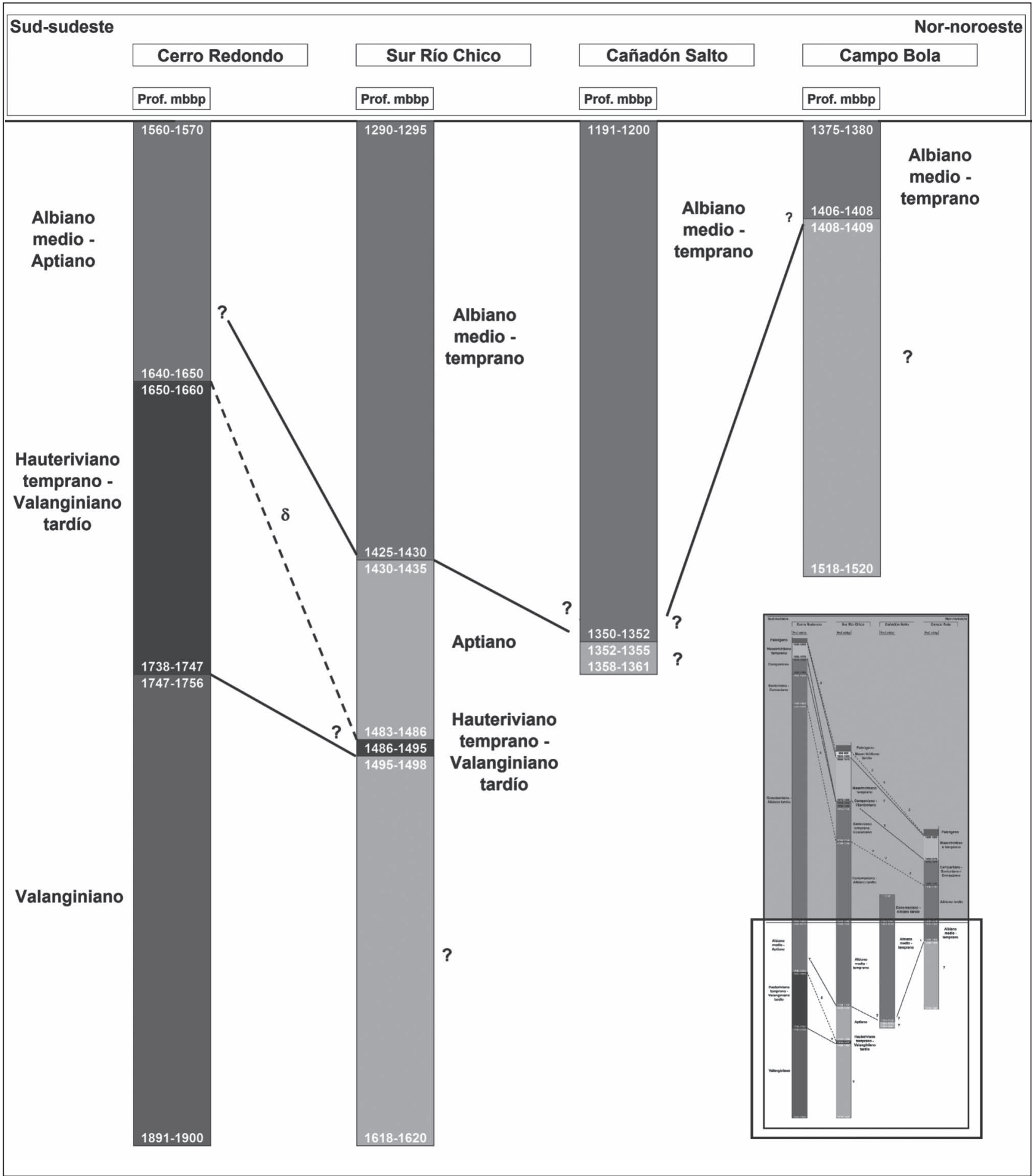

Figura 8. Correlación entre los pozos Cerro Redondo, Sur Río Chico, Cañadón Salto y Campo Bola para el Cretácico Temprano. Las líneas punteadas representan correlaciones con dudas, el signo $\delta$ representa discontinuidades/ Early Cretaceous correlations between Cerro Redondo, Sur Río Chico, Cañadón Salto and Campo Bola boreholes. Dotted lines represent doubtful correlations, the sign $\delta$ represents discontinuities. 


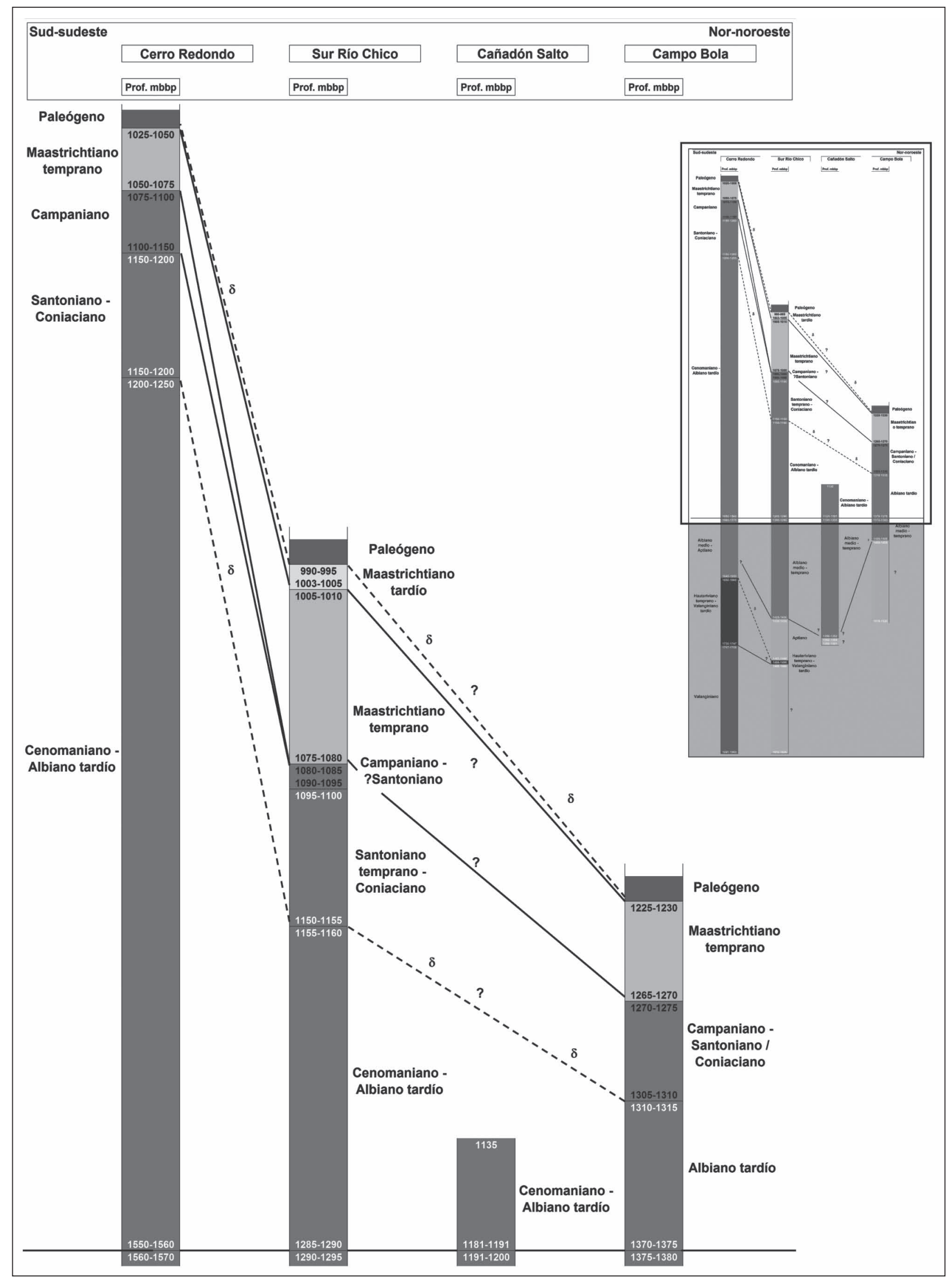


de un enfriamiento importante, tal vez por un cambio en la circulación de las masas de agua antárticas en relación a la continua apertura del Océano Atlántico, de manera que la línea de compensación de la calcita se elevó en la columna de agua. Ambas interpretaciones explicarían la ausencia de microfósiles calcáreos.

Las secuencias asignadas al Albiano temprano-Albiano medio corresponden a arcilitas grises con esporádicos niveles tobáceos e inclusiones de glauconita, y están muy bien caracterizadas por su contenido paleontológico. Las asociaciones de nanofósiles calcáreos presentan una alta biodiversidad y se encuentran en general muy bien preservadas. La edad se interpreta a partir del LAD de Sollasites falklandensis, biomarcador que no supera el Albiano medio en los Plateau de Malvinas, Exmouth y Naturaliste (Pérez Panera, 2011). El valor bioestratigráfico de este bioevento se confirma por la presencia del foraminífero Globigerinelloides gyroidinaeformis (Moullade), biomarcador importante del Albiano medio para la Cuenca Austral (Malumián y Masiuk, 1978; Ronchi y Angelozzi, 1994; Malumián y Náñez, 2002), en las localidades de Cerro Redondo y Sur Río Chico. El LAD de Sollasites falklandensis se reconoce como un biohorizonte importante que permitió establecer un nivel de base confiable para las correlaciones entre las localidades de estudio (ver Figs. 8 y 9). Arkhangelskiella stenostaurion también podría resultar interesante como biomarcador para esta edad en la Cuenca Austral, aunque en otros lugares se la registró hasta el Albiano tardío (Gale et al., 1996; Burnet, 1998; Burnett, 1999; Herrle y Mutterlose, 2003). En las localidades de Campo Bola y Cañadón Salto su LAD se registró a la misma profundidad que el de $S$. falklandensis y en Sur Río Chico y Cerro Redondo, unas muestras por debajo. Asimismo, las asociaciones de nanofósiles calcáreos del Albiano temprano-Albiano medio en la cuenca presentan algunas especies que, si bien tienen biocrones más extensos, suelen ser mucho más abundantes o estar presentes sólo en estos niveles, tal es el caso de Grantarhabdus coronadventis y Grantarhabdus meddii.

Suprayaciendo se disponen sedimentitas de características litológicas similares que contienen una asociación de nanofósiles calcáreos asignados al Albiano tardío-Cenomaniano. Estos niveles están muy bien representados, con importantes espesores sedimentarios (desde los 400 metros en las localidades ubicadas más al sur, hasta los 60 metros en las localidades situadas al norte). Desde el punto de vista de los nanofósiles calcáreos sólo fue posible identificar el límite Albiano-Cenomaniano en las localidades de Sur Río Chico y Cañadón Salto a partir del LAD de Eiffellithus monechiae. En la localidad de Cerro Redondo este bioevento se registra dentro del Aptiano-Albiano medio, lo que sugiere que no se pudo reconocer el verdadero LAD de este biomarcador. Otro bioevento importante que pudo ser reconocido es el LAD de Axpodorhabdus albianus, que ocurre dentro del Cenomaniano tardío (Bralower et al., 1995; Burnett, 1999). En las localidades de Sur Río Chico y Cañadón Salto este biohorizonte se registró en muestras localizadas por encima de aquellas que presentan una asociación de foraminíferos del Albiano tardío y en el caso de Cañadón Salto, también del ostrácodo Majungaella santacruziana; de manera que se refuerza la participación de sedimentitas de edad Cenomaniano. En Campo Bola no se registraron los biomarcadores Axopodorhabdus albianus ni Eiffellithus monechiae, y aunque la asociación de nanofósiles calcáreos responde a las características de una asociación albiana, la asignación de la edad se fundamenta principalmente en los foraminíferos y ostrácodos recuperados. De acuerdo con esto se interpreta que en esa localidad el Cenomaniano no está representado y podría deberse a que se encuentra en una posición marginal de la cuenca, lo que la habría expuesto de manera más intensa a los efectos de la regresión cenomaniana que se produjo en la Cuenca Austral (Malumián y Náñez, 2002).

No se registraron sedimentitas asignables al Turoniano en este sector de la cuenca y se lo interpreta como una discontinuidad entre las sedimentitas del Albiano tardíoCenomaniano y el Coniaciano-Santoniano. Para el caso de la localidad de Campo Bola, la discontinuidad habría involucrado también el Cenomaniano. Charrier y Malumián (1975) reconocen un hiato para el sector oriental de la Cuenca Austral, aunque ellos interpretan que abarca el Cenomaniano-Campaniano temprano. Ronchi y Angelozzi (1994) notaron la ausencia del Cenomaniano tardío-Turoniano en dos localidades en el centro de la cuenca y Concheyro (1995) interpretó un hiato que involucra al menos el Cenomaniano tardío en la perforación Polux X-1 en el este de la Cuenca Austral, costa afuera. Sliter (1976), Concheyro y Angelozzi (2002) y Malumián y Náńez (2002) también identificaron una discontinuidad que, de acuerdo con Sliter (1976), abarcaría desde el Albiano-Cenomaniano tardío hasta el Santoniano en todo el ámbito de los mares australes.

Figura 9. Correlación entre los pozos Cerro Redondo, Sur Río Chico, Cañadón Salto y Campo Bola para el Cretácico Tardío. Las líneas punteadas representan correlaciones con dudas, el signo $\delta$ representa discontinuidades/ Correlation between Cerro Redondo, Sur Río Chico, Cañadón Salto and Campo Bola for the Late Cretaceous. Dotted lines represents doubtful correlations, the sign $\delta$ represents discontinuities. 
Este autor atribuyó la discontinuidad a la deriva continental, cambios climáticos y la circulación oceánica. En parte coincidentemente, Watkins et al. (1996) adviertieron que en toda la región de los mares australes las sedimentitas que corresponden al Turoniano están representadas por pocos metros de potencia o están ausentes. Sin embargo, el Turoniano es reconocido en la Isla Grande de Tierra del Fuego (Flores $e t$ al., 1973; Malumián y Náńez, 1996, 2002) sobre la base del foraminífero Pseudospiroplectinata ona Malumián y Masiuk, y en el sector occidental por los amonites Pachydesmoceras cf. P. linderi (de Grossouvre), Placenticeras sp. y Sciponoceras santacrucense Leanza que indican el Turoniano tardío (Riccardi, 2002).

Suprayaciendo se disponen arcilitas grises o arcilitas tobáceas (i.e. Cerro Redondo) con inclusiones de pirita y esporádicos niveles glauconíticos que corresponderían a facies profundas bajo condiciones de anoxia. Estos niveles tienen una potencia que varía desde los 35 metros en las localidades más septentrionales, hasta los 115 metros en la localidad más austral, Cerro Redondo, portando una asociación de nanofósiles calcáreos del Coniaciano/Santoniano-Campaniano. Estas sedimentitas resultan difíciles de separar de acuerdo a su contenido paleontológico, aún habiéndose recuperado buenos biomarcadores. En relación a esto, y teniendo en cuenta los niveles glauconíticos y las inclusiones de pirita, se interpreta que podría deberse a la existencia de niveles condensados, intercalados con potencias más importantes dadas por las arcilitas tobáceas. En algunas localidades se identificaron nanoeventos reconocidos en otros sectores del Atlántico austral (i.e. Cuenca del Colorado, Plateau de Malvinas), que en general coinciden con la información obtenida a partir de los foraminíferos. El LAD de Reinhardtites anthophorus estaría marcando el techo de la zona CC22 de Sissingh (1977) en el Campaniano tardío y resulta ser el biomarcador más confiable en estas secuencias sedimentarias. En la localidad de Sur Río Chico este bioevento coincide con el LAD del foraminífero Gavelinella murchisonensis (Belford) del Santoniano-Campaniano y en Cerro Redondo con los LAD de los foraminíferos G. murchisonensis y Notoplanulina rokauroana (Finlay), también del Santoniano-Campaniano (Malumián y Masiuk, 1976b). De acuerdo con Wise $(1983,1988)$ y Watkins et al. (1996) el LAD de Biscutum coronum marca el techo de la zona de Biscutum coronum (sensu Wind, 1979a, 1979b) en el Maastrichtiano temprano del hemisferio austral, pero en estas localidades el LAD de Biscutum coronum siempre se registró por debajo del LAD de Reinhardtites anthophorus, y sumado a que los niveles asignados al Maastrichtiano temprano son estériles en nanofósiles calcáreos, este bioevento no resultó de utilidad en este estudio. El LAD de Thiersteinia ecclesiastica y el LAD de Eprolithus foralis permiten interpretar edades no más recientes que ConiacianoSantoniano temprano y Santoniano respectivamente para estos niveles, pero no siempre pudieron observarse en un arreglo cronológico normal. Se asume que estas inconsistencias se deberían a la existencia de niveles condensados.

Por encima de las sedimentitas que contienen la asociación de nanofósiles del Campaniano tardío se disponen niveles arcilíticos que gradan a areniscas arcillosas y que, en la localidad de Campo Bola, culminan con areniscas conglomerádicas con matriz arcillosa. La edad de estas sedimentitas se asigna a partir del contenido microfaunístico ya que resultan estériles en nanofósiles calcáreos. Se recuperó una asociación de foraminíferos aglutinados caracterizada por Haplophragmoides spp., Trochammina texana Cushman y Waters y otras formas de la asociación Spiroplectammina-Textularia sp. que caracterizan la zona informal de "foraminíferos arenáceos" de Malumián y Masiuk (1976a). El desarrollo de sedimentitas con estas características parece ser un patrón que se registra en todo el sector sudoriental de la cuenca y se destaca como uno de los bioeventos más importantes para correlaciones entre las distintas localidades. Esta asociación fue reconocida anteriormente en otros sectores de la cuenca para el ?Campaniano-Maastrichtiano temprano (Flores et al., 1973; Malumián y Masiuk, 1976a, 1978). En la localidad de Sur Río Chico, debido a su posición en la secuencia, esta asociación es atribuida al Maastrichtiano temprano ya que queda comprendida entre una asociación de nanofósiles calcáreos del Campaniano tardío y otra del Maastrichtiano tardío. Malumián y Nánez (1990) y posteriormente Náñez y Malumián (2008) describieron asociaciones de foraminíferos aglutinados en sedimentitas maastrichtianas del sudeste de la provincia de Santa Cruz y en la plataforma, respectivamente. Caramés (1993) reconoció una asociación monoespecífica de Haplophragmoides sp. para el Maastrichtiano de la Formación Calafate, al noroeste de la cuenca. Esta asociación de foraminíferos aglutinados indicaría un ambiente de plataforma interna, de baja energía, bajo condiciones de aguas

Figura 10. Principales nanoeventos e interpretación cronoestratigráfica para el Cretácico del sector sudoriental de la Cuenca Austral, de acuerdo con los resultados obtenidos en el presente estudio. Comparación con las biozonaciones de Sissingh (1977), Watkins et al. (1996) y Wise, (1988)/ Main calcareous nannofossil events and chronostratigraphic interpretation of the Cretaceous in the southeastern area of the Austral Basin, according to the results obtained in the present study. Comparison with the biozonations by Sissingh (1977), Watkins et al. (1996) and Wise (1988). 


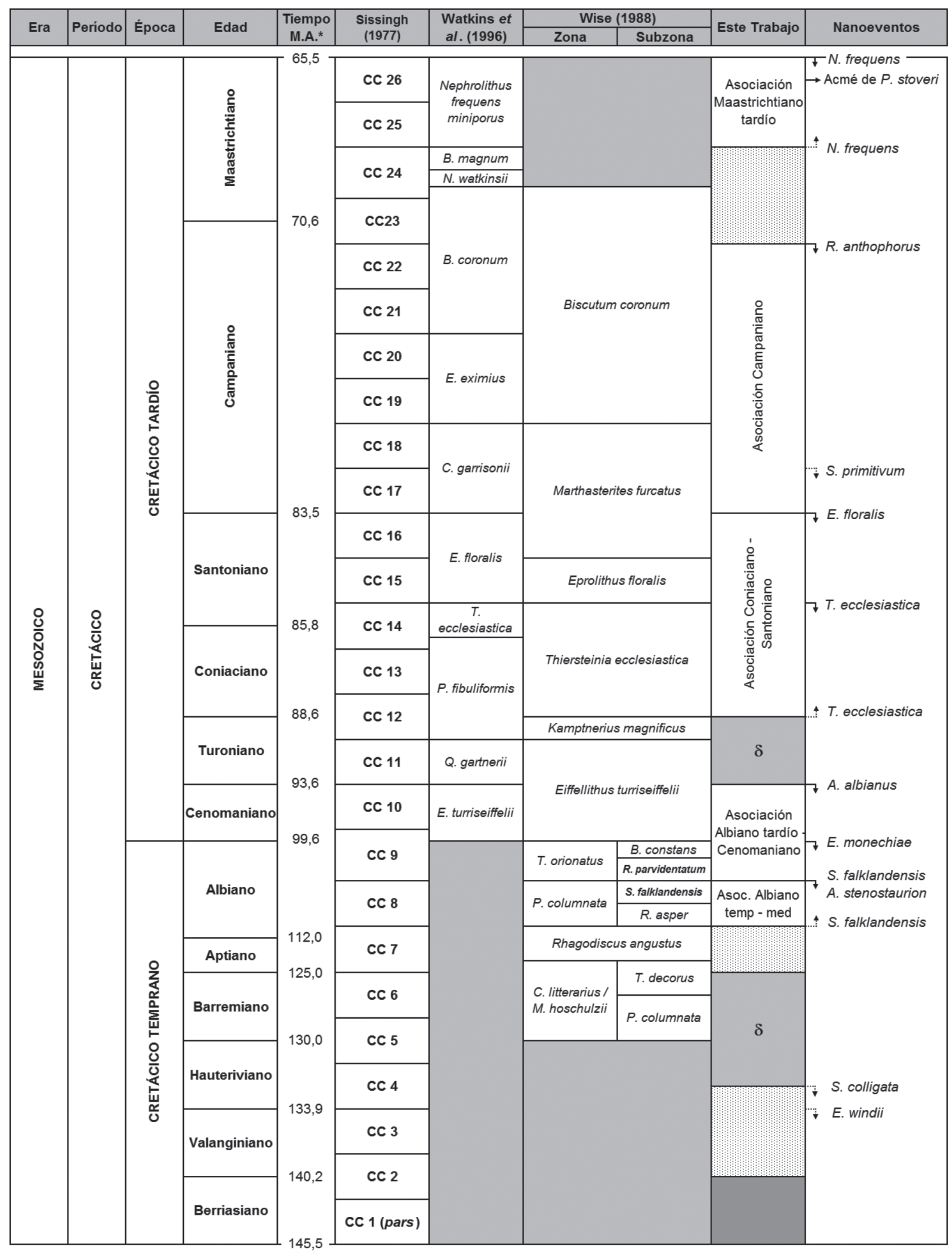


someras e hiposalinas (Náńez y Malumián, 2008); que explicaría, al menos en parte, la ausencia de nanofósiles calcáreos.

Suprayaciendo a estas sedimentitas se desarrollan areniscas arcillosas, en la base glauconíticas, que estarían indicando el inicio de un ciclo transgresivo. Esta transgresión tiene diferentes efectos en las distintas localidades, permitiendo la depositación de sedimentitas asignadas al Maastrichtiano tardío y Paleógeno en Sur Río Chico y al Paleógeno en Cerro Redondo y Campo Bola. En general se interpreta que los niveles del Maastrichtiano tardío se desarrollan en algunos sectores de mayor profundidad y en otros sectores estarían ausentes por procesos de erosión posteriores y/o no depositación. Esta discontinuidad ha sido reconocida en otros sectores de la cuenca y Robbiano et al. (1996) la interpretan como una discordancia relacionada a la instalación de un ciclo regresivo asociado a los movimientos ándicos iniciales. La ausencia de nanofósiles calcáreos y la presencia de una asociación de foraminíferos aglutinados en el Maastrichtiano temprano, junto a la baja diversidad de nanofósiles calcáreos sólo en algunas localidades durante el Maastrichtiano tardío, se interpretan como la instalación de un ambiente marino marginal poco propicio para el desarrollo del nanoplancton calcáreo.

La existencia de sedimentitas asignables al Maastrichtiano tardío se deduce, para la localidad de Sur Río Chico, a partir de la presencia del nanofósil Nephrolithus frequens, importante biomarcador del límite Maastrichtiano/Daniano en el hemisferio austral (Watkins et al., 1996). La presencia del foraminífero Coryphostoma incrassata (Reuss), biomarcador del Maastrichtiano tardío (Ronchi y Angelozzi, 1994; Malumián y Nánez, 2002), confirma la asignación de edad. Se supone que también se desarrollaron sedimentitas del Maastrichtiano tardío en la localidad de San Lorenzo, ya que si bien no se estudiaron las muestras más jóvenes del Cretácico, en el fondo del pozo se recuperaron ejemplares caídos de $\mathrm{Ne}$ prolithus frequens.

\section{AFINIDADES PALEOBIOGEOGRÁFICAS DEL SUDESTE DE LA CUENCA AUSTRAL}

Las asociaciones de nanofósiles calcáreos del Valanginiano-Hauteriviano están muy pobremente representadas. Si bien se reconocieron algunos biomarcadores, la interpretación de edad fue posible mediante el control bioestratigráfico de los foraminíferos asociados. La localidad de San Lorenzo, ubicada más al oeste y próxima al depocentro de cuenca durante este lapso de tiempo, presenta las mejores asociaciones y en ella se reconocieron los biomarcadores Speetonia colliga- ta y Eiffellithus windii. Ambos se registraron en muy pocos niveles y con una abundancia relativa muy baja. Concheyro y Angelozzi (2002) observaron que las asociaciones de nanofósiles calcáreos del Valanginiano-Hauteriviano de la Cuenca Austral y de la Cuenca Neuquina presentan diferencias importantes. En la Cuenca Neuquina Eiffellithus windii, E. striatus, Cruciellipsis cuvillieri y varias especies del género Nannoconus son frecuentes en las asociaciones e incluso importantes biomarcadores. De acuerdo a las características de estas asociaciones, Bown y Concheyro (2004) interpretaron que corresponden a la zona biogeográfica de bajas a medias latitudes (sensu Street y Bown, 2000), y la pobre representación de $S$. colligata y E. windii, sumado a las ausencias de E. striatus, C. cuvillieri y nanocónidos en la Cuenca Austral, estarían evidenciando diferencias biogeográficas importantes. Por otro lado, las asociaciones aquí recuperadas muestran ciertas similitudes con las observadas en el Plateau de Malvinas. En ambas Watznaueria barnesiae, W. britannica, Retecapsa surirella, Discorhabdus ignotus, Zeugrhabdotus embergeri, $Z$. erectus, $Z$. diplogrammus y Cretarhabdus striatus son especies abundantes o frecuentes. Sumado a esto, es interesante que Wise (1983) haya hecho especial referencia a la ausencia de Speetonia colligata, Cruciellipsis cuvillieri y nanocónidos en el Neocomiano del Plateau de Malvinas. Estas características sugieren una íntima relación biogeográfica entre ambas cuencas.

El Albiano temprano y medio está muy bien caracterizado. Presenta una asociación de nanofósiles calcáreos muy diversa y en general muy bien preservada. Ronchi y Angelozzi (1994) y Concheyro y Angelozzi (2002) caracterizaron una asociación albiana muy similar a la registrada en este trabajo, pero llama la atención la ausencia de Sollasites falklandensis. Esta especie, hasta el momento sólo recuperada en el Plateau de Malvinas (Roth y Bowdler, 1981), en el Océano Índico oriental y la India (Bralower y Siesser, 1992; Bralower et al., 1993; Bown et al.,1999) y en el sudeste de Francia (Bralower et al., 1993; Herrle y Mutterlose, 2003); se registra con una abundancia relativa moderada a baja pero es un elemento persistente de las asociaciones del Albiano temprano-Albiano medio de todas las localidades estudiadas, y resulta un biomarcador bioestratigráficamente importante (Pérez Panera, 2011). Wise $(1983,1988)$ estableció que Sollasites falklandensis tiene su origen en el Albiano temprano y se extingue en el Albiano medio. De acuerdo con su bioevento de origen define una subzona para el Plateau de Malvinas. En este trabajo el LAD de Sollasites falklandensis se registró en las localidades de Sur Río Chico y Cerro Redondo, muy próximo 

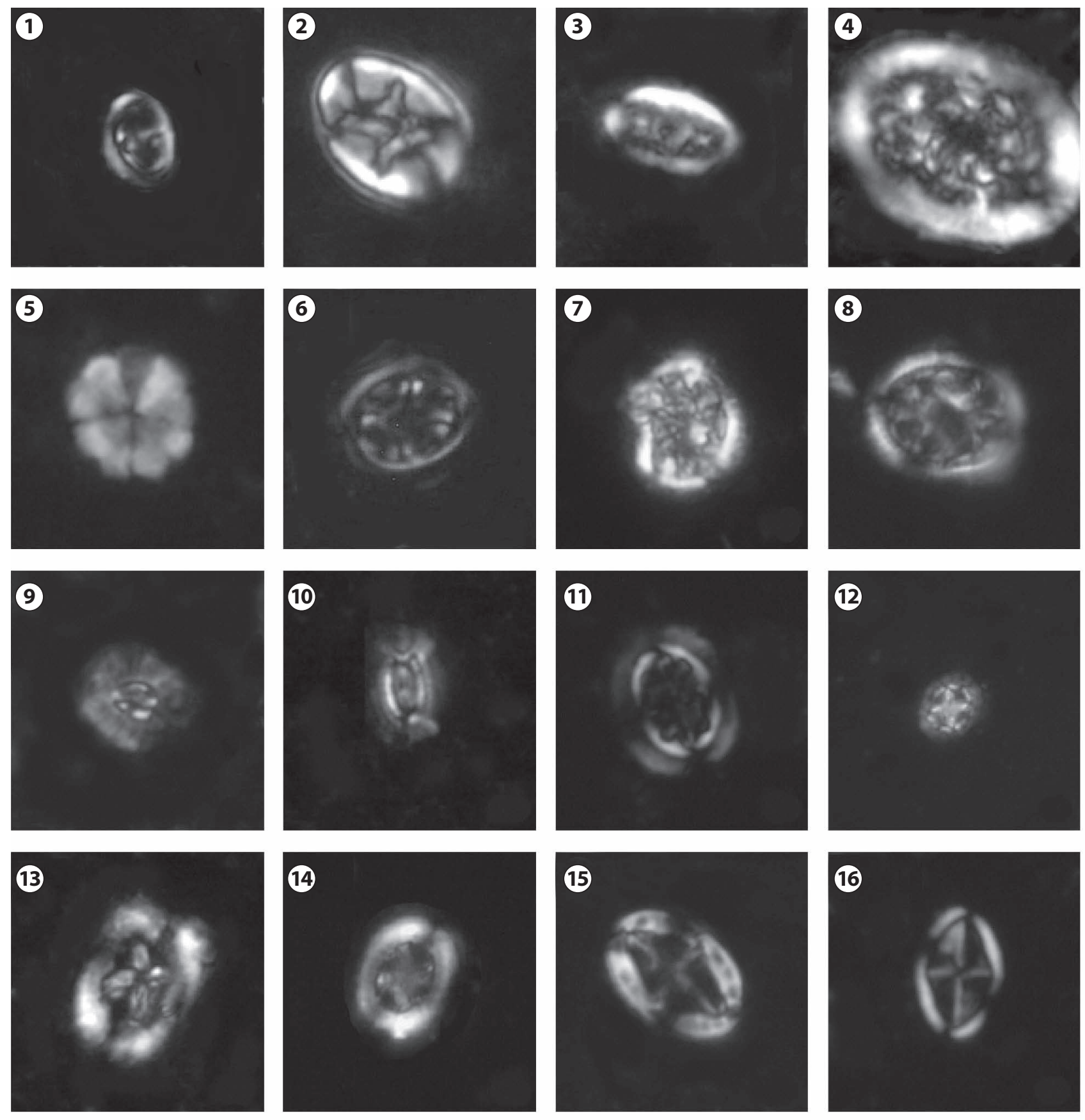

Figura 11. Especies representatitvas de las secciones estudiadas. Todos los especímenes fueron fotografiados bajo luz polarizada. Tamaños entre paréntesis/ Representative species from the studied sections. All specimens photographed under cross-polarized light. Sizes in brackets 1, Reinhardtites anthophorus (Deflandre, 1959) Perch-Nielsen, 1968, BAFC-NP 3435, Cerro Redondo 1100-1150 mbbp, (7 um) 2, Eiffellithus monechiae Crux, 1991, BAFC-NP 3504, Cañadón Salto 1287-1290 mbbp, (6 بm) 3, Rhagodiscus angustus (Stradner, 1963) Reinhardt, 1971, BAFC-NP 3484, Cañadón Salto

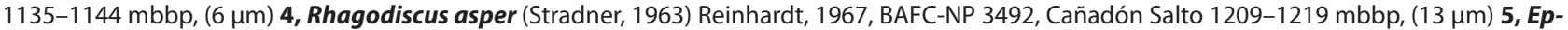
rolithus floralis (Stradner, 1962) Stover, 1966, BAFC-NP 3516, Cañadón Salto 1306-1307 mbbp, (9 4m) 6, Axopodorhabdus albianus (Black, 1967) Wind y Wise, 1983, BAFC-NP 3486, Cañadón Salto 1153-1162 mbbp, (14 um) 7, Nephrolithus frequens Górka, 1957, BAFC-NP 3709, Sur Río Chico

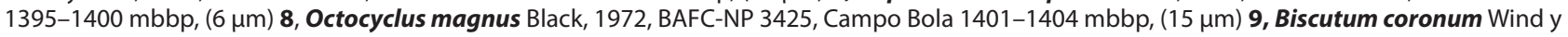
Wise en Wise y Wind, 1977, BAFC-NP 3484, Cañadón Salto 1135-1144 mbbp, $(6 \mu \mathrm{m})$ 10, Seribiscutum primitivum (Thierstein, 1974) Filewicz et al., en Wind y Wise, 1983, BAFC-NP 3485, Cañadón Salto 114-1153 mbbp, $(9 \mu \mathrm{m})$ 11, Sollasites falklandensis Filewicz et al. en Wise y Wind, 1977, BAFCNP 3417, Campo Bola 1375-1380 mbbp, (9 um) 12, Prediscosphaera columnata (Stover, 1966) Perch-Nielsen, 1984, BAFC-NP 3457, Cerro Redondo 1620-1630 mbbp, $(6 \mu \mathrm{m})$ 13, Grantarhabdus coronadventis (Reinhardt, 1966) Grün en Grün y Allemann, 1975, BAFC-NP 3483, Cañadón Salto 1135 mbbp, $(14 \mu \mathrm{m})$ 14, Grantarhabdus meddii Black, 1971, BAFC-NP 3421, Campo Bola 1389-1392 mbbp, $(10 \mu \mathrm{m})$ 15, Thiersteinia ecclesiastica Wise y Watkins en Wise, 1983, BAFC-NP 3421, Campo Bola 1389-1392 mbbp, (10 um) 16, Arkhangelskiella stenostaurion (Hill, 1976) Herrle y Mutterlose, 2003, BAFC-NP 3417, Campo Bola 1375-1380 mbbp, (7 $\mu \mathrm{m})$. 
al LAD del foraminífero Globigerinelloides gyroidinaeformis (Moullade), biomarcador del Albiano temprano-Albiano medio (Malumián y Náñez, 2002). La identificación de Sollasites falklandensis en la Cuenca Austral tiene valor regional porque permite vincular paleogeográfica y paleoceanográficamente esta cuenca con el Plateau de Malvinas. De acuerdo a Wise y Wind (1977) las asociaciones albianas del Plateau de Malvinas presentan cierto grado de provincialismo o endemismo y corresponderían a un ambiente de aguas superfciales templadas a frías. Otras especies que son características de las asociaciones recuperadas en este trabajo y de las asociaciones del Plateau de Malvinas son Seribiscutum primitivum, Repagulum parvidentatum, Biscutum dissimilis, Crucibiscutum salebrosum y Octocyclus magnus todas con reconocida afinidad por las altas latitudes. Las asociaciones del Albiano tardío-Cenomaniano, en general, están caracterizadas por una marcada abundancia relativa de las especies Repagulum parvidentatum, Seribiscutum primitivum, Biscutum constans, Watznaueria barnesiae, Zeugrhabdotus diplogrammus y Zeugrhabdotus erectus (ver Archivos Complementarios 1-4), características que también se observan en las asociaciones del Plateau de Malvinas (Wise y Wind, 1977; Wise, 1983). Las dos primeras son especies restringidas a altas latitudes de aguas superficiales frías y $Z$. diplogrammus, $Z$. erectus y $B$. constans, presentan una marcada afinidad a mares epicontinentales y ambientes inestables con alta concentración de nutrientes en las aguas superficiales (Roth, 1986, 1989; Roth y Bowdler, 1981; Roth y Krumbach, 1986; Wise, 1988; Crux, 1991a; Erba, 1992; Street y Bown, 2000; Mutterlose et al., 2009). Es importante remarcar también que durante el Albiano las asociaciones de nanofósiles se distribuyen más en función de la disponibilidad de nutrientes que en función de la temperatura (Roth y Bowdler, 1981; Roth, 1989); de manera que las características de las asociaciones aquí recuperadas y las del Plateau de Malvinas presentarían similitudes tanto paleogeográficas como paleoambientales. Por otro lado, W. barnesiae es una especie de reconocida resistencia a la disolución, que florece en ambientes oceánicos de aguas superficiales con baja concentración de nutrientes. Sin embargo, W. barnesiae sería en realidad una especie oportunista con un alto grado de tolerancia ecológica y capaz de explotar ambientes estresantes con alta concentración de nutrientes (Roth y Bowdler, 1981; Mutterlose y Wise, 1990). En este sector de la Cuenca Austral, la alta abundancia relativa de W. barnesiae es acompañada por moderadas a altas abundancias relativas de otras especies del género Watznaueria (i.e. W. fossacincta, W. biporta, W. britannica, W. sp. 1), lo que apuntaría a considerar que estas especies presentan características paleoecológicas similares.

Por lo antedicho se interpreta que durante el Albiano-Cenomaniano, este sector de la Cuenca Austral presentaba condiciones de circulación oceánica similares a las del Plateau de Malvinas, con aguas superficiales templado-frías y en mares someros con buena disponibilidad de nutrientes. Concheyro y Angelozzi (2002) interpretaron condiciones similares para el sector central de la cuenca. Una diferencia importante que presentan las asociaciones recuperadas en este trabajo y las del Plateau de Malvinas es la escasa abundancia de especímenes del género Nannoconus. Para el Albiano, las formas del grupo Nannoconus truitti son comunes en casi todas las muestras del Plateau de Malvinas, mientras que en la Cuenca Austral, con la excepción de unos pocos especímenes de Nannoconus kamptneri en una muestra de Cañadón Salto, este grupo de nanofósiles está ausente. Estas diferencias podrían deberse a condiciones ecológicas poco propicias para los nannocónidos en la Cuenca Austral. La presencia de especies del género Nannoconus en el Plateau de Malvinas está muy vinculada a Braarudosphaera africana (Wise y Wind, 1977; Wise, 1983) y en general a otros pentalitos (i.e. Braarudosphaera sp., Micrantholithus sp.), con los que comparte una afinidad a plataformas internas (Bown, 2005). Braarudosphaera africana no fue registrada en este trabajo pero está citada para la Cuenca Austral (Concheyro y Angelozzi, 2002) y es una especie muy bien representada para el océano Atlántico. En las muestras analizadas en este trabajo, los pentalitos son poco abundantes a través de toda la secuencia cretácica. Se asume que los nannocónidos son un grupo de afinidad a aguas cálidas, ambientes neríticos en plataformas internas carbonáticas, muy bien representados en la región del Tethys (Erba, 1994; Street y Bown, 2000; Bown, 2005); mientras que los pentalitos no muestran preferencias en cuanto a la temperatura de las aguas (Crux, 1991a; Street y Bown, 2000). En este sentido, la pobre representación de nannocónidos junto con la escasa abundancia de pentalitos, sugeriría un ambiente de mar epicontinental, de plataforma externa y aguas superficiales frías, probablemente algo más profundo en la Cuenca Austral que en el Plateau de Malvinas.

Las asociaciones del Coniaciano/Santoniano-Campaniano presentan en general una buena diversidad y estado de preservación. Estas secuencias, en las localidades más septentrionales se desarrollan en pocos metros y presentarían niveles condensados. Se reconocen importantes biomarcadores como Eprolithus floralis y Thiersteinia ecclesiastica, esta última especie muy característica de los océanos australes y que vincula las asociaciones aquí recuperadas con las aso- 
ciaciones del Plateau de Malvinas. Concheyro y Angelozzi (2002) encontraron en el área central de la Cuenca Austral, asociaciones de baja diversidad y poco representativas. Las asociaciones del Campaniano tardío-Maastrichtiano tardío, en cambio, presentan una diversidad más pobre y, excepto por Nephrolithus frequens, están dominadas por especies de distribución cosmopolita; coincidentemente con lo que observaron Concheyro y Angelozzi (2002). Un rasgo importante de estas asociaciones es la escasa presencia de especies del complejo Monomarginatus-Misceomarginatus, formas muy características del Plateau de Malvinas durante el Campaniano tardío-Maastrichtiano, que también fueron recuperadas en el Mar de Weddell y la Antártida (Crux, 1991b; Robles Hurtado y Concheyro, 1995, 2002).

Paleobiogeográficamente, las asociaciones de nanofósiles calcáreos durante el Campaniano-Maastrichtiano de la Cuenca Austral presentan características muy similares a las de la Cuenca Neuquina (Concheyro y Nánez, 1994; Concheyro, 1995; Concheyro y Villa, 1997; Keller et al., 2007) y la Cuenca del Colorado (Pérez Panera y Angelozzi, 2006) con abundancia de especies cosmopolitas y algunas otras típicas de altas latitudes, que corresponderían a la provincia biogeográfica Transicional del Atlántico Sur (sensu Wind, 1979a). Para esos tiempos las diferencias con la provincia paleogeográfica del Plateau de Malvinas eran más marcadas y, como ya se dijo, la virtual ausencia de especies del complejo Monomarginatus-Misceomarginatus es el rasgo más conspicuo. Concheyro (1995) interpretó las mismas características paleobiogeográficas para la asociación de nanofósiles que recupera en el Maastrichtiano de la plataforma de Cuenca Austral.

En la Figura 11 se ilustran algunas de las especies más importantes desde el punto de vista bioestratigráfico y paleobiogeográfico reconocidas en este trabajo.

\section{CONCLUSIONES}

Se reconocieron asociaciones de nanofósiles calcáreos en buen estado de preservación y con alta diversidad para el Cretácico del sector sudoriental de Cuenca Austral. Estas asociaciones están mejor representadas para el Albiano-Cenomaniano y el Coniaciano/Santoniano-Campaniano.

Las asociaciones de nanofósiles calcáreos permiten deducir la edad de las sedimentitas de la secuencia cretácica sobre la base de una buena representación y abundancia de especies biomarcadoras, tanto de carácter local, como cosmopolitas. Se evidencia la importancia de poder contar con información independiente aportada por otras disciplinas como control bioestratigráfico, lo que ha permitido establecer biohorizontes con un mayor grado de confianza e incluso datar ciertos tramos de la secuencia cretácica donde los nanofósiles calcáreos presentaban características confusas.

Se reconocen varios taxones con valor bioestratigráfico y paleobiogeográfico, y se identifican algunos con potencial como biomarcadores locales. Eiffellithus windii y Speetonia colligata para el Valanginiano-Hauteriviano, ArkhangelskieIla stenostaurion, Grantarhabdus coronadventis, G. meddii, Octocyclus magnus, O. reinhardtii, Prediscosphaera columnata, Repagulum parvidentatum, Seribiscutum primitivum y Sollasites falklandensis, para el Aptiano-Albiano medio. Axopodorhabdus albianus, Eiffellithus monechiae, Prediscosphaera columnata, P. cretacea, Repagulum parvidentatum, Rhagodiscus angustus, $R$. asper y Seribiscutum primitivum para el Albiano tardío-Cenomaniano, Biscutum coronum, Calculites obscurus, Eprolithus floralis, Kamptnerius magnificus, Repagulum parvidentatum, Seribiscutum primitivum, y Thiersteinia ecclesiastica para el Coniaciano/Santoniano-Campaniano. Ahmuellerella octoradiata, Arkhangelskiella cymbiformis, Biscutum coronum, B. magnum, Cribrosphaerella ehrenbergii, Kamptnerius magnificus, Micula staurophora, Reinhardtites anthophorus y Repagulum parvidentatum para el Campaniano tardío, y Ahmuellerella octoradiata, Arkhangelskiella cymbiformis, A. maastrichtiana, Cribrosphaerella ehrenbergii, Kamptnerius magnificus, Micula concava, M. staurophora, Prediscosphaera microrhabdulina, P. stoveri y Nephrolithus frequens para el Maastrichtiano tardío.

El estudio de las asociaciones de nanofósiles calcáreos ha permitido reconocer dos discontinuidades para la secuencia cretácica que se extienden en todo el sector sudoriental de la cuenca. Las mismas corresponden a un hiato bioestratigráfico que abarca al menos el Barremiano y otro que abarca al menos el Turoniano.

Se interpreta que durante el Valanginiano-Cenomaniano, el sector sudeste de la Cuenca Austral presenta una nanoflora fósil con características muy similares a las registradas para el Plateau de Malvinas y durante el Albiano se habrían desarrollado condiciones de temperatura, disponibilidad de nutrientes y circulación de masas de agua comparables.

Durante el Campaniano tardío-Maastrichtiano las características de las asociaciones de nanofósiles calcáreos están estrechamente vinculadas a las registradas para la Cuenca Neuquina y Cuenca del Colorado y corresponderían a una zona biogeográfica de temperaturas templadas a frías asignable a la provincia Transicional (sensu Wind, 1979a). 


\section{AGRADECIMIENTOS}

Este estudio se basa, en parte, en la tesis doctoral presentada por el autor en la Universidad Nacional de La Plata, Argentina, en Abril del 2010; titulada: "Sistemática y Biostratigrafía de los Nanofósiles Calcáreos del Cretácico del Sudeste de la Cuenca Austral, Santa Cruz, Argentina.” El mismo fue posible gracias a la empresa Petrobras-Energía S.A., que a través de M. Cagnolatti y F. Pángaro, generosamente proveyó las muestras. La empresa GEMA S.R.L. brindó ayuda con equipamiento para el estudio. Se agradece especialmente a D. Ronchi, quién llevó a cabo el estudio de los microfósiles y a G. Angelozzi quién colaboró en la tarea de la interpretación bioestratigráfica de los pozos estudiados. Se extiende el agradecimiento al revisor Dr. Aguado Merlo, quien con sus sugerencias hizo posible que este trabajo mejorara y a un revisor anónimo por sus correcciones. El Dr. J.D. Daza Vaca colaboró en la edición de las figuras. Este estudio fue financiado por el CONICET a través de los subsidios PIP 5613 y PIP 00819.

\section{APÉNDICE A}

\section{Lista de especies citadas en el texto}

Ahmuellerella octoradiata (Górka, 1957) Reinahrdt, 1966a

Arkhangelskiella cymbiformis Vekshina, 1959

Arkhangelskiella maastrichtiana Burnett, 1998

Arkhangelskiella stenostaurion (Hill, 1976) Herrle y Mutterlose, 2003

Axopodorhabdus albianus (Black, 1967) Wind y Wise, 1983

Biscutum coronum Wind y Wise en Wise y Wind, 1977

Biscutum dissimilis Wind y Wise en Wise y Wind, 1977

Biscutum magnum Wind y Wise en Wise y Wind, 1977

Braarudosphaera africana Stradner, 1961

Braarudosphaera bigelowii (Gran y Braarud, 1935) Deflandre, 1947

Broinsonia matalosa (Stover, 1966) Burnett en Gale et al., 1996

Broinsonia signata (Noël, 1969) Noël, 1970

Calculites obscurus (Deflandre, 1959) Prins y Sissingh en Sissingh, 1977

Chiastozygus garrisonii Bukry, 1969

Chiastozygus litterarius (Górka, 1957) Manivit, 1971

Corollithion cf. C. exiguum Stradner, 1961

Cretarhabdus conicus Bramlette y Martini, 1964

Cretarhabdus striatus (Stradner, 1963) Black, 1973

Cribrosphaerella ehrenbergii (Arkhangelsky, 1912) Deflandre en Piveteau, 1952

Cribrosphaerella daniae Perch-Nielsen, 1973

Crucibiscutum hayi (Black, 1973) Jakubowski, 1986

Crucibiscutum salebrosum (Black, 1971) Jakubowski, 1986

Cruciellipsis cuvillieri (Manivit, 1966) Thierstein, 1971

Discorhabdus ignotus (Górka, 1957) Perch-Nielsen, 1968

Eiffellithus eximius (Stover, 1966) Perch-Nielsen, 1968

Eiffellithus monechiae Crux, 1991b
Eiffellithus striatus (Black, 1971) Applegate y Bergen, 1988

Eiffellithus turriseiffelii (Deflandre en Deflandre y Fert, 1954)

Reinhardt, 1965

Eiffellithus windii Applegate y Bergen, 1988

Eprolithus floralis (Stradner, 1962) Stover, 1966

Gartnerago obliquum (Stradner, 1963) Reinhardt, 1970

Grantarhabdus coronadventis (Reinhardt, 1966a) Grün en

Grün y Allemann, 1975

Grantarhabdus meddii Black, 1971

Kamptnerius magnificus Deflandre, 1959

Markalius inversus (Deflandre en Deflandre y Fert, 1954)

Bramlette y Martini, 1964

Micrantholithus hoschulzii (Reinhardt, 1966a) Thierstein, 1971

Micula concava (Stradner en Martini y Stradner, 1960) Verbeek, 1976

Micula staurophora (Gardet, 1955) Stradner, 1963

Nannocunus kamptneri Brönnimann, 1955

Nannoconus truitti Brönnimann, 1955

Nephrolithus frequens Gorka, 1957

Nephrolithus frequens miniporus (Reinhardt y Gorka, 1967)

Pospichal y Wise, 1990

Octocyclus magnus Black, 1972

Octocyclus reinhardtii (Bukry, 1969) Wind y Wise en Wise y Wind, 1977

Prediscosphaera columnata (Stover, 1966) Perch-Nielsen, 1984

Prediscosphaera cretacea (Arkhangelsky, 1912) Gartner, 1968

Prediscosphaera microrhabdulina Perch-Nielsen, 1973

Prediscosphaera spinosa (Bramlette y Martini,1964) Gartner, 1968

Prediscosphaera stoveri (Perch-Nielsen, 1968) Shafik y Stradner, 1971

Radiolithus planus Stover, 1966

Reinhardtites anthophorus (Deflandre, 1959) Perch-Nielsen, 1968

Reinhardtites levis Prins y Sissingh en Sissingh, 1977

Repagulum parvidentatum (Deflandre y Fert, 1954) Forchheimer, 1972

Retecapsa surirella (Deflandre y Fert, 1954) Grün en Grün y Allemann, 1975

Rhagodiscus angustus (Stradner, 1963) Reinhardt, 1971

Rhagodiscus asper (Stradner, 1963) Reinhardt, 1967

Seribiscutum primitivum (Thierstein, 1974) Filewicz et al. en Wind y Wise, 1983

Sollasites falklandensis Filewicz et al. en Wise y Wind, 1977

Sollasites horticus (Stradner et al. en Stradner y Adamiker, 
1966) Čepek y Hay, 1969

Speetonia colligata Black, 1971

Staurolithites crux (Deflandre y Fert, 1954) Caratini, 1963

Staurolithites zoensis Burnett, 1998

Stoverius achylosus (Stover, 1966) Perch-Nielsen, 1986

Thiersteinia ecclesiastica Wise y Watkins en Wise, 1983

Tranolithus orionatus (Reinhardt, 1966a) Reinhardt, 1966b

Tranolithus phacelosus Stover, 1966 (= Tranolithus orionatus)

Watznaueria barnesiae (Black en Black y Barnes, 1959)

Perch-Nielsen, 1968

Watznaueria biporta Bukry, 1969

Watznaueria britannica (Stradner, 1963) Reinhardt, 1964

Watznaueria fossacincta (Black, 1971) Bown en Bown y Cooper, 1989

Watznaueria sp. 1

Zeugrhabdotus diplogrammus (Deflandre en Deflandre y Fert, 1954) Burnett en Gale et al., 1996

Zeugrhabdotus embergeri (Noël, 1958) Perch-Nielsen, 1984

Zeugrhabdotus erectus (Deflandre en Deflandre y Fert, 1954)

Reinhardt, 1965

Zeugrhabdotus scutula (Bergen, 1994) Rutledge y Bown, 1996

Zeugrhabdotus trivectis Bergen, 1994

\section{REFERENCIAS}

Aguirre-Urreta, M.B. 2002. Invertebrados del Cretácico inferior. En: M.J. Haller (Ed.), Geología y Recursos Naturales de Santa Cruz. $15^{\circ}$ Congreso Geológico Argentino (El Calafate) Relatorio, p. 439-459.

Angelozzi, G.N., Ronchi, D.I. y Pérez Panera, J.P. 2008. Asociaciones de nanofósiles calcáreos y foraminíferos del Mioceno Temprano del Atlántico sur occidental. $4^{\circ}$ Congreso del Regional Commitee on Atlantic Neogene Stratigraphy (Buenos Aires), Resumenes, p. 12-13.

Applegate, J.L. y Bergen, J.A. 1988. Cretaceous calcareous nannofossil biostratigraphy of sediments recovered from the Galicia Margin, ODP Leg. 103. Proceedings of the Ocean Drilling Program, Scientific Results 103: 293-348.

Arbe, H.A. 1989. Estratigrafía, discontinuidades y evolución sedimentaria del Cretácico en la Cuenca Austral, Provincia de Santa Cruz. En: L. Spalletti y G. Chebli (Eds.), Cuencas Sedimentarias Argentinas. Serie Correlación Geológica (INSUGEO) 6: 419-442.

Arkhangelsky, A.D. 1912. Verkhenemelovya otolozheniga vostoka europeyskog rosii (Upper Cretaceous deposits of east European Russia). Materialien zur Geologie Russlands 25: 1-631.

Ballent. S.C., Ronchi, D.I. y Whatley, R. 1998. The ostracod genus Majungaella Grekoff in Argentina. Revista Geológica de Chile 25: 45-55.

Bergen, J.A. 1994. Berriasian to early Aptian calcareous nannofossils from the Vocotonian Trough (SE France) and Deep Sea Drilling Site 534: new nannofossil taxa and a summary of low-latitude biostratigraphic events. Journal of Nannoplankton Research 16: 59-69.

Biddle, K.T., Uliana, M.A., Mitchum Jr., R.M., Fitzgerald, M.G. y Wright, R.C. 1986. The Stratigraphic and structural evolution of the central and eastern Magallanes basin, southern South America. En: P.A. Allen y P. Homewoods (Eds.), Foreland Basins. Special Publication 8, International Association of Sedimentologists, p. 41-61.
Black, M. 1967. New names for some coccolith taxa. Proceedings of the Geological Society, London 1640: 139-145.

Black, M. 1971. Coccoliths of the Speeton Clay and Sutterby Marl. Proceedings of the Yorkshire Geological Society 38: 381-424.

Black, M. 1972. British Lower Cretaceous Coccoliths. I - Gault Clay (part 1). Palaeontological Society of London Monograph 126: 1-48.

Black, M. 1973. British Lower Cretaceous Coccoliths. I - Gault Clay (part 2). Palaeontological Society of London Monograph 127: 49-112.

Black, M. y Barnes, B. 1959. The structure of Coccoliths from the English Chalk. Geological Magazine 96: 321-328.

Blasco de Nullo, G., Nullo, F. y Proserpio, C.A. 1980. Santoniano-Campaniano: Estratigrafía y contenido ammonitífero. Cuenca Austral. Revista de la Asociación Geológica Argentina 35: 467-499.

Bown, P.R. 2005. Early to Mid-Cretaceous Calcareous Nannoplankton from the Northwest Pacific Ocean, Leg 198, Shatsky Rise. [En línea] Proceedings of the Ocean Drilling Program, Scientific Results, 198: 1-82. <http://www-odp.tamu.edu/publications/198_SR/114/114.htm> [Consulta: 02 de febrero de 2007].

Bown, P.R. y Concheyro, A. 2004. Lower Cretaceous nannoplankton from the Neuquén Basin, Argentina. Marine Micropaleontology 52: 51-84.

Bown, P.R. y Cooper, M.K.E. 1989. New calcareous nannofossils from the Jurassic. Journal of Micropalaeontology 8: 91-96.

Bown, P.R., Rutledge, D.C., Crux, J.A. y Gallagher, L.T. 1999. Lower Cretaceous. En: P.R. Bown (Ed.), Calcareous Nannofossil Biostratigraphy, $2^{\text {nd }}$ edition. British Micropalaeontological Society Publications Series, Kluwer Academic Publishers, London. p. 86-131.

Bralower, T.J. and Siesser, W.G. 1992. Cretaceous calcareous nannofossil biostratigraphy of sites 761, 762 and 763, Exmouth and Wombat Plateaus, Northwest Australia. Proceedings of the Ocean Drilling Program, Scientific Results 122: 529-556.

Bralower, T.J., Leckie, R.M., Sliter, W.V. y Thierstein, H.R. 1995. An integrated Cretaceous microfossil biostratigraphy. En: W.A. Berggren, D.V. Kent, M.P. Aubry y J. Hardenbol (Eds.), Geochronology, time scales and global stratigraphic correlation. SEPM Special Publications 54: 65-79.

Bralower, T.J., Sliter, W.V., Arthur, M.A., Leckie, R.M., Allard, D. and Schlanger, S.O. 1993. Dysoxic/Anoxic Episodes in the Aptian-Albian (Early Cretaceous). In: M.S. Pringle, W.W. Sager, W.V. Sliter and S. Stain (Eds.), The Mesozoic Pacific: geology, tectonics and volcanism. American Geophysical Union, Geophysical Monograph 77, p. 5-37.

Bramlette, M.N. y Martini, E. 1964. The great change in calcareous nannoplankton fossils between the Maastrichtian and Danian. Micropalaento$\log 10: 291-322$.

Bramlette, M.N. y Sullivan, F.R. 1961. Coccolithophorids and related nannoplankton of the early Tertiary in California. Micropaleontology 2: 129-188.

Brönnimann, P. 1955. Microfossils incertae sedis from the Upper Jurassic and Lower Cretaceous of Cuba. Micropaleontology 1: 28-51

Bukry, D. 1969. Upper Cretaceous coccoliths from Texas and Europe. The University of Kansas Paleontological Contributions, Article 51 (Protista 2): $1-79$.

Burnett, J.A. 1998. New taxa and new combinations of Cretaceous nannofossils, and a note on the origin of Petrarhabdus (Deflandre) Wind \& Wise. Journal of Nannoplankton Research 19: 133-146.

Burnett, J.A. 1999. Upper Cretaceous. En: P.R. Bown (Ed.), Calcareous Nannofossil Biostratigraphy, $2^{\text {nd }}$ edition. British Micropalaeontological Society Publications Series, Kluwer Academic Publishers, London, p. 132-199.

Caramés, A. 1993. [Foraminiferos y bioestratigrafía del Cretácico Superior $y$ Terciario Inferior del Sur de Argentina. Tesis Doctoral. Facultad de Ciencias Exactas y Naturales, Universidad Nacional de Buenos Aires, 1: 1-208; 2: 1-178. Inédito.]. 
Caratini, C. 1963. Contribution à l'étude des coccolithes du Cénomanien supérieur et du Turonien de la région de Rouen. Thèse, Université d'Alger, Faculté des Sciences. Publication du Laboratoire de Géologique Appliquée, p. 1-61.

Carrizo, R., Malumián, N., Nánez, C., Caramés, A. y Concheyro, A. 1990. Micropaleontología y correlación del Terciario del área carbonífera de Río Turbio, provincia de Santa Cruz, Argentina. $2^{\circ}$ Simposio sobre el Terciario de Chile. Procesos y Productos de Depositación en el ámbito Andino. Actas 1: 29-50.

Čepek, P. y Hay, W.W. 1969. Calcareous nannoplankton and biostratigraphic subdivision of the Upper Cretaceous. Transactions of the Gulf Coast Association of Geological Societies 19: 323-336.

Charrier, R. y Lahsen, A.A. 1968. Contribution a l'etude de la limite Crétacé-Tertiaire de la Province de Magellan, extreme Sud du Chili. Revue de Micropaléontologie 11: 11-120.

Charrier, R. y Lahsen, A.A. 1969. Stratigraphy of the Late Cretaceous-Early Eocene Seno Skyring - Strait of Magellan Area, Magallanes Province, Chili. Bulletin of the American Association of Petroleum Geologists 53: 568-590.

Charrier, R. y Malumián, N. 1975. Orogénesis y epirogénesis en la región austral de América del Sur, durante el Mesozoico y el Cenozoico. Revista de la Asociación Geológica Argentina, 3: 193-207.

Concheyro, A. 1991. Nanofósiles calcáreos de la Formación Man Aike (Eoceno, Sudeste del Lago Cardiel) Santa Cruz, Argentina. Ameghiniana 28: 385-399.

Concheyro, A. 1995. [Nanofósiles calcáreos del Cretácico Superior y Paleógeno de Patagonia, Argentina. Tesis Doctoral. Facultad de Ciencias Exactas y Naturales, Universidad Nacional de Buenos Aires, 1: 1-133; 2: 1-176. Inédito.].

Concheyro, A. 2002. Upper Jurassic and Cretaceous calcareous nannofossils from James Ross Island, Snow Hill Island and Antartic Peninsula. $9^{\circ}$ International Nannoplankton Association Conference (Parma), Journal of Nannoplankton Research, Abstracts 24: 85.

Concheyro, A. y Angelozzi, G.N. 2002. Nanofósiles calcáreos de la provincia de Santa Cruz, Argentina. En: M.J. Haller (Ed.), Geología y recursos naturales de la provincia de Santa Cruz. $15^{\circ}$ Congreso Geológico Argentino (El Calafate), Relatorio, p. 495-517.

Concheyro, A. y Náñez, C. 1994. Microfossils and biostratigraphy of the Jagüel and Roca Formations (Maestrichtian-Danian), Province of Neuquén. Ameghiniana, Suplemento Resúmenes 31: 397-398.

Concheyro, A. y Villa, G. 1996. Maestrichtian-Danian (K/P) calcareous nannofossils in the Liu Malal section. Northern Patagonia, Argentina. Palaeopelagos 6: 281-297.

Crux, J.A. 1991a. Albian calcareous nannofossils from the Gault Clay of Munday's Hill (Bedfordshire, Engalnd). Journal of Micropalaeontology 10: 203-221.

Crux, J.A. 1991b. Calcareous nannofossils recovered by Leg 114 in the Subantartic South Atlantic Ocean. Proceedings of the Ocean Drilling Program, Scientific Results 114: 155-177.

Deflandre, G. 1947. Braarudosphaera nov. gen., type d'une famille nouvelle de Coccolithophoridés actuels à éléments composites. Comptes Rendus (Hebdomadaires des Séances) de l'Académie des Sciences de Paris 225: 439-441.

Deflandre, G. 1959. Sur les nannofosiles calcaires et leur systématique. Revue de Micropaléontologie 2: 127-152.

Deflandre, G. y Fert, C. 1954. Observations sur les Coccolithophoridés actuels et fossiles en microscopie ordinaire et électronique. Annales de Paléontologie 40: 115-176.

Erba, E. 1992. Middle Cretaceous calcareous nannofossils from the western Pacific (ODP Leg 129): evidence for palaeoequatorial crossings. Proceedings of the Ocean Drilling Program, Scientific Results 129: 189-201.
Erba, E. 1994. Nannofossils and superplumes: The early Aptian "Nannoconid crisis." Paleoceanography 9: 483-501.

Feruglio, E. 1949. Descripción Geológica de la Patagonia, volumen 1. Dirección General Yacimientos Petroliferos Fiscales, Buenos Aires, 329 p.

Flores, M.A., Malumián, N., Masiuk, V. y Riggi, J.C. 1973. Estratigrafía cretácica del subsuelo de Tierra del Fuego. Revista de la Asociación Geológica Argentina 28: 407-437.

Forchheimer, S. 1972. Scanning Electron Microscope studies of Cretaceous coccoliths from the Köpingsberg Borehole $N^{\circ} 1$, SE Sweden. Sveriges Geologiska Undersökning, Series C \#668, 65: 1-141.

Gale, A.S., Kennedy, W.J., Burnett, J.A., Caron, M. y Kidd, B.E. 1996. The Late Aptian to Early Cenomanian succession at Mont Risou, near Rosans (Drôme, SE France): an integrated study (ammonites, inoceramids, planktonic foraminifera, nannofossils, oxygen and carbon isotopes). Cretaceous Research 17: 515-606.

Gardet, M. 1955. Contribution à l'étude des coccolithes des terrains néogènes de l'Algérie. Publications du Service de la Carte Géologique de l'Algérie (Nouvelle Série) 5: 477-550.

Gartner, S. 1968. Coccoliths and related calcareous nannofossils from Upper Cretaceous deposits of Texas and Arkansas. The University of Kansas Paleontological Contributions, Article 48 (Protista 1): 1-56.

Gartner, S. 1977. Nannofossils and Biostratigraphy: An Overview. EarthScience Reviews 13: 227-250.

Górka, H. 1957. Les Coccolithophoridés du Maestrichtien supérieur de Pologne. Acta Palaeontologica Polonica 2: 239-284.

Gran, H.H. y Braarud, T. 1935. A quantitative study of the phytoplankton in the Bay of Fundy and the Gulf of Maine (including observations on hydrography, chemistry and turbidity). Journal of the Biological Board of Canada 1: 279-467.

Grün, W. y Allemann, F. 1975. The Lower Cretaceous of Caravaca (Spain): Berriasian Calcareous Nannoplankton of the Miravetes Section (Subbetic Zone, Prov. Of Murcia). Eclogae Geologicae Helvetiae 68: 147-211.

Haller, M.J. (Ed.) 2002. Geología y Recursos Naturales de Santa Cruz. $15^{\circ}$ Congreso Geológico Argentino (El Calafate), Relatorio, p. 1-925.

Hernández, M.P., Concheyro, A., Lazo, D., Rodríguez, D., Aguirre-Urreta, M.B., Ottone, E.G. 2005. Asociaciones palinológicas, nanofósiles calcáreos e invertebrados del Miembro Agua de la Mula, Formación Agrio, en su localidad tipo, provincia del Neuquén. En E. Llambías, R. de Barrio, P. González y P. Leal (Eds.), $16^{\circ}$ Congreso Geológico Argentino (La Plata), Actas versión CD-Room, p. 1-8.

Herrle, J.O. y Mutterlose, J. 2003. Calcareous nannofossils from the Aptian-Lower Albian of southeast France: palaeoecological and biostratigraphic implications. Cretaceous Research 24: 1-22.

Hill, M.E. 1976. Lower Cretaceous calcareous nannofossils from Texas and Oklahoma. Palaeontographica, Abteilung B 156: 103-179.

Jakubowski, M. 1986. New calcareous nannofossil taxa from the Lower Cretaceous of the North Sea. International Nannoplankton Association Newsletter 8: 38-42.

Keller, G., Adatte, T., Tantawy, A.A., Berner, Z., Stinnesbeck, W., Stueben, D. y Leanza, H.A. 2007. High stress late Maastrichtian-early Danianpalaeoenvironment in the Neuquén Basin, Argentina. Cretaceous Research 28: 939-960

Kraemer, P.E. y Riccardi, A.C. 1997. Estratigrafía de la región comprendida entre los lagos Argentino y Viedma, Santa Cruz. Revista de la Asociación Geológica Argentina 52: 333-360.

Leanza, A.F. 1972. Andes Patagónicos Australes. En: A.F. Leanza (Ed.), Geología Regional Argentina. Academia Nacional de Ciencias, Córdoba, p. 689-706.

Lescano, M.A. y Concheyro, A. 2009. Nanofósiles calcáreos de la Formación Agrio (Cretácico Inferior) en el sector sudoccidental de la Cuenca Neuquina, Argentina. Ameghiniana 46: 73-94.

Malumián, N. 1970. Bioestratigrafía del Terciario marino del subsuelo de la provincia de Buenos Aires (Argentina). Ameghiniana 7: 173-204. 
Malumián, N. 1990. Foraminíferos bentónicos del Cretácico de Cuenca Austral, Argentina. En: W. Volkheimer (Ed.), Bioestratigrafia de los sistemas regionales del Jurásico y Cretácico de América del Sur (Mendoza, 1986). Comité Sudamericano del Jurásico y Cretácico, p. 429-495.

Malumián, N. 1999. La sedimentación y el volcanismo terciarios en la Patagonia extraandina. En: R. Caminos (Ed.), Geología Argentina. Anales del Instituto de Geología y Recursos Minerales 29: 557-612.

Malumián, N. 2002. El Terciario Marino. Sus relaciones con el eustatismo. En: M.J. Haller (Ed.), Geología y Recursos Naturales de Santa Cruz. $15^{\circ}$ Congreso Geológico Argentino (El Calafate), Relatorio, p. 237-244.

Malumián, N. y Caramés, A. 1997. Upper Campanian-Paleogene from Río Turbio coal measures area: micropaleontology and the Paleocene/Eocene boundary. Journal of South American Earth Sciences 10: 189-201.

Malumián, N. y Masiuk, V. 1975. Foraminíferos de la Formación Pampa Rincón (Cretácico inferior) Tierra del Fuego. Revista Española de Paleontología 7: 579-600.

Malumián, N. y Masiuk, V. 1976a. Foraminíferos característicos de las Formaciones Nueva Argentina y Arroyo Alfa, Cretácico Inferior, Tierra del Fuego, Argentina. $6^{\circ}$ Congreso Geológico Argentino (Bahía Blanca), Actas, p. 393-411.

Malumián, N. y Masiuk, V. 1976b. Foraminíferos de la Formación Cabeza de León (Cretácico Superior, Tierra del Fuego, Rep. Argentina). Revista de la Asociación Geológica Argentina 31: 180-202.

Malumián, N. y Masiuk, V. 1978. Foraminíferos planctónicos del Cretácico de Tierra del Fuego. Revista de la Asociación Geológica Argentina 33: $37-51$

Malumián, N. y Náñez, C. 1990. Foraminíferos aglutinados del Cretácico Superior de cuenca Austral (Provincia de Santa Cruz), Argentina. En: W. Volkheimer (Ed.), Bioestratigrafía de los Sistemas regionales del Jurásico y Cretácico de América del Sur. (Mendoza, 1986). Comité Sudamericano del Jurásico y Cretácico, p. 497-551.

Malumián, N. y Náñez, C. 1996. Microfósiles y nanoplancton calcáreo de la Plataforma Continental. En: V.A. Ramos y M.A. Turic (Eds.), Geologia y Recursos Naturales de la Plataforma Continental Argentina. $13^{\circ}$ Congreso Geológico Argentino y $3^{\circ}$ Congreso de Exploración de Hidrocarburos (Buenos Aires), Relatorio, p. 73-93.

Malumián, N. y Náñez, C. 2002. Los foraminíferos. Su significado geológico y ambiental. En: M.J. Haller (Ed.), Geología y Recursos Naturales de Santa Cruz. $15^{\circ}$ Congreso Geológico Argentino (El Calafate), Relatorio, p. 481-493.

Malumián, N., Masiuk, V. y Riggi, J.C. 1971. Micropaleontología y sedimentología de la perforación SC-1, provincia de Santa Cruz, República Argentina, su importancia y correlaciones. Revista de la Asociación Geológica Argentina 24: 175-208.

Malumián, N., Nullo, F. y Ramos, V. 1983. The Cretaceous of Argentina, Chile, Paraguay and Uruguay. En: M. Moullade y A.E.M. Nair (Eds.), The Fanerozoic Geology of the World II. The Mesozoic. Elsevier, Amsterdam, p. 265-304.

Manivit, H. 1966. Sur quelques coccolithes nouveax du Néocomien. Compte Rendue Sommarie de la Société Géologique de France 7: 267-268.

Manivit, H. 1971. [Les Nannofossiles calcaires du Crétacé francais (AptienMaestrichtien). Essai de Biozonation appuyée sur les stratotypes. Thése Doctoral d'Etat, Faculté des Sciences d'Orsay, Université de París. pp. 187. Inédito.].

Martini, E. y Stradner, H. 1960. Nannotetraster, eine stratigraphisch bedeutsame neue Discoasteridengattung. Erdöel-Zeitschritf76: 266-270.

Masiuk, V. y Ronchi, D.I. 1981. [Correlación de pozos de Cuenca Austral. Informe interno de YPF, Buenos Aires, p. 1-26. Inédito.]

Mostajo, E.L. 1991. Nanofósiles calcáreos cenozóicos del Pozo „Las Violetas 3“. Isla Grande de Tierra del Fuego. Argentina. Ameghiniana 28: 311-315.

Mutterlose, J. y Wise, S.W. 1990. Lower Cretaceous nannofossil biostratigraphy of ODP Leg 113 Holes 692B and 693A, continental slope off east Antarctica, Weddell Sea. Proceedings of the Ocean Drilling Program, Scientific Results 113: 325-351.

Mutterlose, J., Bornemann, J. y Herrle, J. 2009. The Aptian-Albian cold snap: Evidence for "mid" Cretaceous icehouse interludes. Neues Jahrbuch für Geologie und Paläontologie, Abhandlungen 252: 217-225.

Náñez, C. y Malumián, N. 2008. Paleobiogeografía y paleogeografía del Maastrichtiense marino de la Patagonia, Tierra del Fuego y la Plataforma Continental Argentina, según sus foraminíferos bentónicos. Revista Española de Paleontología 23: 273-300.

Noël, D. 1958. Étude de coccolithes du Jurassique et du Crétacé inférieur. Publications du Service de la Carte Géologique de l'Algérie (Nouvelle Série), Bulletin 20: 155-196.

Noël, D. 1969. Structure de quelques coccolithes du Crétacé supérieur du Bassin de Paris examinés au microscope électronique. Proceedings of the

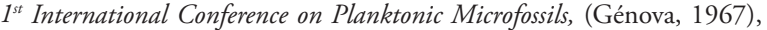
2: 475-485.

Noël, D. 1970. Coccolithes Crétacés: La Craie Campanienne du Bassin de Paris. Éditions du Centre National de la Recherche Scientifique, Paris, p. 129.

Nullo, F.E., Panza, J.L. y Blasco, G. 1999. Jurásico y Cretácico de la Cuenca Austral. En: R. Caminos (Ed.), Geología Argentina. Anales del Instituto de Geología y Recursos Minerales 29: 528-535.

Nullo, F.E., Proserpio, C.A. y Blasco, G. 1981a. El Cretácico de la Cuenca Austral entre Lago San Martín y Río Turbio. En: W. Volkheimer (Ed.), Cuencas Sedimentarias del Jurásico y Cretácico de América del Sur. Comité Sudamericano del Jurásico y Cretácico, Buenos Aires, p. 181-220.

Nullo, F.E., Proserpio, C.A. y Blasco, G. 1981b. Estratigrafía del Cretácico superior en el cerro Índice y alrededores. $8^{\circ}$ Congreso Geológico Argentino (San Luis), Actas, 3: 373-387.

Perch-Nielsen, K. 1968. Der Feinbau und die Klassifikation der Coccolithen aus dem Maastrichtien von Dänemark. Det kongelige Danske Videnskabernes Selskab Biologiske Skrifter 16: 1-93.

Perch-Nielsen, K. 1973. Neue coccolithen aus dem Maastrichtien von Dänemark, Madagaskar und Ägypten. Bulletin of the Geological Society of Denmark 22: 306-333.

Perch-Nielsen, K. 1984. Validation of new combinations. International Nannoplankton Association Newsletter 6: 42-46.

Perch-Nielsen, K. 1986. New Mesozoic and Paleogene calcareous nannofossils. Eclogae Geologicae Helvetiae 79: 835-847.

Pérez Panera, J.P. 2007. Avances en la micropaleontología del subsuelo de la Cuenca Austral, Argentina: nanofósiles calcáreos. Ameghiniana, Suplemento Resúmenes 44: 98R

Pérez Panera, J.P. 2009. Nanofósiles calcáreos paleógenos del sudeste de la provincia de Santa Cruz, Patagonia, Argentina. Ameghiniana 46: 273-284.

Pérez Panera, J.P. 2010. Nanofósiles calcáreos del Albiano temprano-medio de la Cuenca Austral, Argentina. $10^{\circ}$ Congreso Argentino de Paleontología y Bioestratigrafía y $7^{\circ}$ Congreso Latinoamericano de Paleontología (La Plata), Resúmenes, p. 96-97.

Pérez Panera, J.P. 2011. The calcareous nannofossil Sollasites falklandensis (Coccolithophyceae) and its biostratigraphic and palaeoceanographic importance in the Albian of Austral Basin, Argentina. Cretaceous Research 32: 723-737.

Pérez Panera, J.P. y Angelozzi, G.N. 2006. Nanofósiles calcáreos del Cretácico Tardío-Terciario, del Pozo BB III A x-1 (Bahía Blanca), Cuenca del Colorado, Argentina. Ameghiniana 43: 557-565.

Piveteau, J. 1952. Traité de paléontologie, Tome 1. Masson, París, p. 107115.

Pospichal, J.J. y Wise, S.W. 1990. Maastrichtian calcareous nannofossil biostratigraphy of Maud Rise ODP Leg 113 Sites 689 and 690, Weddell Sea. Proceedings of the Ocean Drilling Program, Scientific Results 113: 465-487. 
Reinhardt, P. 1964. Einige Kalkflagellaten-Gattungen (Coccolithophoriden, Coccolithineen) aus dem Mesozoikum Deutschlands. Monastberichte der Deustchen Akademie der Wissenschaften zu Berlin 6: 749-759.

Reinhardt, P. 1965. Neue Familien für fossile Kalkflagellaten (Coccolithophoriden, Coccolithineen). Monatsberichte der Deutschen Akademie der Wissenschaften zu Berlin 7: 30-40.

Reinhardt, P. 1966a. Zur Taxionomie und Biostratigraphie des fossilen Nannoplanktons aus dem Malm. der Kreide und dem Alttertiär Mitteleuropas. Freiberger Forschungshefte C 196: 5-109.

Reinhardt, P. 1966b. Fossile Vertreter coronoider und styloider Coccolithen (Family Coccolithaceae Poche 1913). Monatsberichte der Deutschen Akademie der Wissenschaften zu Berlin 8: 513-524.

Reinhardt, P. 1967. Fossile Coccolithen mit rhagoidem Zentralfeld (Fam. Ahmuellerellaceae, Subord. Coccolithineae) Neues Jahrbuch für Geologie und Paläontologie, Monatshefte 1967: 163-178.

Reinhardt, P. 1970/71. Synopsis der Gauttungen und Arten der mesozoischen Coccolithen und anderer Kalkiger Nannofossilien, I, II, III (1971). Freiberger Forschungshefte C 260: 5-32; 265: 41-111; 267: 19-41.

Reinhardt, P. y Górka, H. 1967. Revision of some Upper Cretaceous Coccoliths from Poland and Germany. Neues Jahrbuch für Geologie und Paläontologie, Abhandlungen 129: 240-256.

Riccardi, A.C. 1984. Las asociaciones de amonitas del Jurásico y Cretácico de la Argentina. $9^{\circ}$ Congreso Geológico Argentina (Bariloche), Actas, 4: 559-595.

Riccardi, A.C. 1988. The Cretaceous System of Southern South America. Memoir of the Geological Society of America 168: 1-161.

Riccardi, A.C. 2002. Invertebrados del Cretácico superior. En: M.J. Haller (Ed.), Geología y Recursos Naturales de Santa Cruz. $15^{\circ}$ Congreso Geológico Argentino (El Calafate), Relatorio, p. 461-479.

Riccardi, A.C. y Rolleri, E.O. 1980. Cordillera Patagónica Ausrtal. Geología Regional Argentina, Segundo Simposio. Academia Nacional de Ciencias, Córdoba, 2: 1173-1306.

Robbiano, J.A., Arbe, H.A. y Gangui, A. 1996. Cuenca Austral Marina. En: V.A. Ramos y M.A. Turic (Eds.), Geología y Recursos Naturales de la Plataforma Continental Argentina. 13 ${ }^{\text {er }}$ Congreso Geológico Argentino y $3^{\text {er }}$ Congreso de Exploración de Hidrocarburos (Buenos Aires), Relatorio, p. 323-341.

Robles Hurtado, G.M. y Concheyro, A. 1995. Sedimentología y Biocronoestratigrafía (nanofósiles calcáreos) del Nunatak Sanctuary Cliffs (Cretácico superior) Isla Cerro Nevado, Antártida. $6^{\circ}$ Congreso Argentino de Paleontología y Bioestratigrafía (Trelew), Actas 2: 231-237.

Rodríguez, J.F. y Miller, M. 2005. Cuenca Austral. En: G.A. Chebli, J.S. Cortińas, L.A. Spalletti, L. Legarreta, y E.L. Vallejo (Eds.), Frontera Exploratoria de la Argentina. $6^{\circ}$ Congreso de exploración y Desarrollo de Hidrocarburos (Mar del Plata), Actas, p. 307-323.

Ronchi, D.I. y Angelozzi, G.N. 1994. Bioestratigrafía del Cretácico-Terciario en dos pozos ubicados al oeste de la Cuenca Austral. BIP (Boletín de Informaciones Petroleras) 39: 65-76.

Rossi de García, E. y Camacho, H.H. 1965. Descripción de fósiles procedentes de una perforación efectuada en la provincia de Santa Cruz (Argentina). Ameghiniana 4: 71-74.

Roth, P.H. 1986. Mesozoic palaeoceanography of the North Atlantic and Tethys Oceans. In: C.P. Summerhayes and N.J. Shackleton (Eds.), North Atlantic Palaeoceanography. Geological Society Special Publication 20: 299-320.

Roth, P.H. 1989. Ocean circulation and calcareous nannoplankton evolution during the Jurassic and Cretaceous. Palaeogeography, Palaeoclimatology, Palaeoecology 74: 111-126.

Roth, P.H. y Bowdler, J.L. 1981. Middle Cretaceous calcareous nannoplankton biogeography and oceanography of the Atlantic Ocean. SEPM (Society for Sedimentary Geology) Special Publication 32: 517-546.

Roth, P.H. y Krumbach, K.R. 1986. Middle Cretaceous calcareous nannofossil biogeography and preservation in the Atlantic and Indian
Oceans: Implications for paleoceanography. Marine Micropaleontology 10: 235-266.

Roth, P.H. y Thierstein, H. 1972. Calcareous nannoplankton: Leg 14 of the Deep Sea Drilling Project. Initial Reports of the Deep Sea Drilling Project 14: $421-485$.

Rutledge, D. y Bown, P.R. 1996. New names for old: taxonomic clarification of some Early Cretaceous nannofossil marker-species. Journal of Nannoplankton Research 18: 53-59.

Shafik, S. y Stradner, H. 1971. Nannofossils from the Eastern Desert, Egypt. Jahrbuch der Geologischen Bundesanstalt, Sonderband 17: 69-104.

Shamrock, J.L. y Watkins, D.K. 2009. Evolution of the Cretaceous calcareous nannofossil genus Eiffellithus and its biostratigraphic significance. Cretaceous Research 30: 1083-1102.

Sissingh, W. 1977. Biostratigraphy of Cretaceous calcareous nannoplankton. Geologie en Mijnbouw 56: 37-65.

Sliter, W.V. 1976. Cretaceous foraminifers from the Southwestern Atlantic Ocean, Leg 36, Deep Sea Drilling Project. Initial Reports of the Deep Sea Drilling Project 36: 519-573.

Stover, L.E. 1966. Cretaceous coccoliths and associated nannofossils from France and the Netherlands. Micropaleontology 12: 133-167.

Stradner, H. 1961. Vorkommen von Nannofossilien im Mesozoikum und Altteriär. Erdoël-Zeitschrift fuer Bohr und Foerdertechnik 77: 77-88.

Stradner, H. 1962. Über neue und wenig bekannte Nannofossilien aus Kreide und Alttertiär. Sonderabdruck aus den Verhandlungen der Geologischen Bundesanstalt 2: 363-377.

Stradner, H. 1963. New contributions to Mesozoic stratigraphy by means of nannofossils. Proceedings of the Sixth World Petroleum Congress. Section 1, p. 167-183.

Stradner, H. y Adamiker, D. 1966. Nannofossilien aus Bohrkernen und ihre elektronenmikroskopische Bearbeitung. Erdöel-Erdgas-Zeitschrift 82: 330-341.

Street, C. y Bown, P.R. 2000. Paleobiogeography of Early Cretaceous (Berriasian-Barremian) calcareous nannoplankton. Marine Micropaleontology 39: 265-291.

Thierstein, H.R. 1971. Tentative Lower Cretaceous Calcareous Nannoplankton Zonation. Eclogae Geologicae Helvetiae 64: 459-488.

Thierstein, H.R. 1974. Calcareous nannoplankton - Leg 26, Deep Sea Drilling Project. Initial Reports of the Deep Sea Drilling Project 26: 619-667.

Thierstein, H.R., Geitzenauer, K.R., Molfino, B. y Shackleton, N. 1977. Global synchroneity of the Late Quaternary coccolith datum levels: validation by oxygen isotopes. Geology 5: 400-404.

Varol, O. 1992. Taxonomic revision of the Polycyclolithaceae and its contribution to Cretaceous biostratigraphy. Newsletters in Stratigraphy 27: 93-127.

Vekshina, V.N. 1959. Coccolithophoridae of the Maastrichtian deposits of the West Siberian Lowlands. Siberian Science Research Institute of Geology, Geophysics, Mineralogy and Raw Materials 2: 56-81.

Verbeek, J.W. 1976. Upper Cretaceous nannoplankton zonation in a composite section near El Kef, Tunisia. Proceedings of the Koninklijke Nederlandse Akademie van Wetenschappen B 79: 129-148.

Watkins, D.K., Wise, S. W., Pospichal, J.J. y Crux, J. 1996. Upper Cretaceous calcareous nannofossil biostratigraphy and paleoceanography of the Southern Ocean. En: A. Moguilevsky y R. Whatley (Eds.) Microfossils and Oceanic Environments. University of Wales, Aberystwyth Press, pp. 355-381.

Wind, F.H. 1979a. Maestrichtian-Campanian nannoflora provinces of the southern Atlantic and Indian Oceans. En: M. Talwani, W.W. Hay y W.B.F. Ryan (Eds.), Deep Sea Drilling Results in the Atlantic Ocean: Continental Margins and Paleoenvironment, Maurice Ewing Series 3: 123-137.

Wind, F.H. 1979b. [Late Campanian and Maastrichtian calcareous nannoplankton biogeography and high-latitud biostratigraphy. PhD Thesis dissertation. Florida State University, Tallahassee. Inédito.]. 
Wind, F.H. y Wise, S.W. 1983. Correlation of Upper Campanian-Lower Maastrichtian calcareous nannofossil assemblages in drill and piston cores from the Falkland Plateau, Southwest Atlantic Ocean. Initial Reports of the Deep Sea Drilling Project 71: 551-563.

Wise, S.W. 1983. Mesozoic and Cenozoic calcareous nannofossils recovered by DSDP Leg 71 in the Falkland Plateau region, Southwest Atlantic Ocean. Initial Reports of the Deep Sea Drilling Project 71: 481-550.

Wise, S.W. 1988. Mesozoic-Cenozoic history of calcareous nannofossils in the regeion of the Southern Ocean. Palaeogeography, Palaeoclimatology, Palaeoecology 67: 157-179.

Wise, S.W. y Wind, F.H. 1977. Mesozoic and Cenozoic calcareous nannofossils recovered by DSDP Leg 36 drilling on the Falkland Plateau, south-west Atlantic sector of the Southern Ocean. Initial Reports of the Deep Sea Drilling Project 36: 269-491.
Zilli, N., Pedrazzini, M. y Peroni, G. 2002. La Cuenca Austral. En: M.J. Haller (Ed.), Geología y Recursos Naturales de Santa Cruz. $15^{\circ}$ Congreso Geológico Argentino (El Calafate), Relatorio, p. 607-662.

doi: 10.5710/AMGH.v49i2(377)

Recibido: 17 de julio de 2010

Aceptado: 5 de marzo de 2011 